\title{
RECENCY EFFECTS IN JUSTICE AND ORGANIZATIONAL CITIZENSHIP BEHAVIOR: THE IMPACT OF COPING STYLE
}

\author{
Juliana Lilly \\ Sam Houston State University • Huntsville, Texas \\ Meghna Virick \\ San Jose State University • San Jose, California \\ Kamphol Wipawayangkool \\ Sam Houston State University • Huntsville, Texas
}

\section{ABSTRACT}

The present study examines the incremental effects of interpersonal and informational justice over three time periods on organizational citizenship behavior (OCB). Fairness heuristic theory and uncertainty management theory are used to examine whether initial justice perceptions are consistently influential over time on OCB creating a primacy effect, or if later justice perceptions are more influential on OCB than initial ones creating a recency effect. Results indicate a possible recency effect in longitudinal justice perceptions. Additionally, two individual coping styles, approach and avoidance, were examined as moderators of the justice/ OCB relationship. It was hypothesized that higher levels of avoidance coping would make justice perceptions more influential in predicting $\mathrm{OCB}$, but higher levels of approach coping would make justice perceptions less influential in predicting OCB. The hypotheses were mostly supported for OCB directed toward individuals, but not for OCB directed toward the organization.

Keywords: justice over time, organizational citizenship behavior, uncertainty management theory, coping

\section{INTRODUCTION}

The justice literature has slowly begun to examine the dynamic nature of justice, with some studies attempting to predict within person differences of justice perceptions over time (Holtz and Harold 2009; Lilly, Virick, and Hadani 2010) and other studies focusing on the incremental impact of justice over time on outcome variables (Ambrose and Cropanzano 2003; Hausknecht, Sturman, and Roberson 2011; Kim, Lin and Leung 2015). Despite the interest in longitudinal justice effects, there still remains a dearth of studies on the topic and a lack of clear focus on applicable theory. 
This study contributes to the literature by examining the impact of longitudinal justice perceptions on Organizational Citizenship Behavior (OCB), a critical component in healthy organizational functioning (Podsakoff, Mackenzie, Paine, and Bachrach 2000), and investigating the impact of individual coping style to ascertain if individual coping style ameliorates the fairness effect which proposes that fair procedures tend to override negative reactions to unfavorable decision outcomes (Folger, Rosenfield, Grove, and Corkran 1979; Lind 2001). The purpose of this study is to examine whether initial justice perceptions are consistently influential over time on OCB, creating a primacy effect, or if later justice perceptions are more influential on OCB than initial ones, creating a recency effect. In addition, we examine whether (a) approach coping, or trying to change the situation by confronting the situation, and (b) avoidance coping, or trying to avoid dealing with the situation (Roth and Cohen 1986) decrease the impact of justice on OCB.

Studying the effects of justice over time on OCB along with coping moderators of this relationship may help explain with more clarity specific situations in which the impact of justice is decreased. For example, are there some circumstances in which justice perceptions create a primacy effect? In other words, once initial justice perceptions are formed, do they continue to influence attitudes and behaviors over time or does the influence weaken over time? Do individual traits such as coping style reduce the fairness effect? From a theoretical perspective, answers to these questions may provide conceptual insights not currently addressed by theory. From a practical perspective, answers may provide managers with more tools to use when trying to manage employee behavior.

\section{LITERATURE REVIEW}

\section{The Influence of Justice in the Workplace}

Justice perceptions have always been important because of their influence on important behavioral outcomes, such as OCB. OCB is helping behavior in organizations that is commonly broken into two categories: (a) behavior directed toward the overall organization; and (b) behavior directed toward particular individuals in the organization (McNeely and Meglino 1994; Williams and Anderson 1991). Organizational justice is generally considered an antecedent of OCB (Fassina, Jones, and Uggerslev 2008; Moorman and Byrne 2005), and researchers have suggested that OCBs are related to organizational effectiveness (see Podsakoff, et al. 2000, for a review). We chose OCB as the outcome variable of interest because of its long 
history of being related to justice perceptions and because of its importance in the effective functioning of an organization. Thus, any research that helps to clarify the antecedents of OCB is a worthwhile endeavor. To this end of clarifying antecedents, we focus on two dimensions of justice - interpersonal justice and informational justice.

Interpersonal justice refers to the person implementing the decision process and concerns whether the person demonstrated respect and politeness while implementing the process. Informational justice concerns issues such as explaining the decision procedures thoroughly and in a timely manner. We believe interpersonal and informational justice are the most relevant in the current study for reasons outlined below.

Interpersonal and informational justice, although susceptible to incorrect perceptions about the individuals involved, focus on the people involved in implementing and communicating processes and outcomes, people who often are the only person employees see representing organizational policies. In fact, studies have linked interpersonal justice to extra-role behaviors such as those found in OCB (Aquino 1995; Colquitt 2001). Colquitt and Rodell (2011) suggest that informational justice is critical in creating reciprocating exchanges in the form of OCBs. Thus we believe interpersonal and informational justice represent the true nature of employee perceptions of justice as it pertains to examining OCB under potential uncertainty.

\section{Justice over Time}

A number of justice studies have suggested that justice over time is important in the workplace, with some research examining the impact of initial justice perceptions on subsequent events and perceptions. For example, researchers have found that justice measured at time 1 has an impact on perceptions of test fairness three weeks later (Bauer, Maertz, Dolen, and Campion 1998), on actual turnover measured three years later (Tekleab, Takeuchi, and Taylor 2005), and on the acceptability of arbitrators by disputing parties three months later (Posthuma, Dworkin, and Swift 2000). These studies suggest that initial perceptions of justice are somewhat constant over time. In contrast to these studies, other researchers have examined how justice perceptions over time tend to fluctuate depending upon favorability of a particular outcome (Ambrose and Cropanzano 2003; Thornhill and Saunders 2003). Studies have also focused on explaining specific within-subject differences in justice over time (Holtz and Harold 2009; Kim, et al. 2015; Lilly et al. 2010) or the incremental impact of justice over time (Hausknecht et al. 2011). 
A common element seemingly prevalent in more recent studies is that they have struggled to find a unifying theory of justice that fully accounts for justice over time. Part of the problem may be due to the various uses of time itself in justice research. For example, does justice over time refer to justice perceptions of a single event measured at different points over time? Does it refer to initial perceptions of justice impacting other variables over time? Does it refer to perceptions of both current and future events impacting perceptions of justice as time unfolds? The reference point for justice (initial and ending) along with the variables impacted may lead to various theories being used to account for justice over time.

Earlier studies using social exchange theory (Blau 1964), equity theory (Adams 1963), or organizational justice theory based on the fairness effect (Lind 2001) were primarily interested in examining how initial perceptions of justice influenced later variables (Bauer et al. 1998; Posthuma et al. 2000; Tekleab et al. 2005; Thornhill and Saunders 2003). Thus, the stability found in social exchange relationships, equity comparisons, and the fairness effect was sufficient in explaining the results.

Recent studies, however, have focused more on explaining within-subject differences in justice over time or on the incremental impact of justice over time on specific outcome variables. We believe it is more difficult for researchers to use social exchange theory, equity theory and the fairness effect when studying changes in perceptions over time. For example, assume a researcher predicts justice perceptions of an initial event to fluctuate from high to low over several time periods. Using the norm of reciprocity in social exchange as the basis of a hypothesis, the researcher would have to predict the exchange relationship itself somehow changed at each measured time period. Using equity theory, the researcher would have to predict the equity fraction used for comparison changed at each measured time period. Using the fairness effect would not work at all, since the premise of the fairness effect is that once individuals perceive fair procedures at work, perceptions of fairness would carry over to other aspects in the workplace, regardless of sporadic events over time that could alter previous fairness perceptions. The question, then, concerns whether perceptions of justice over time are stable, creating a primacy effect created by initial perceptions, or whether perceptions of justice change over time, creating a recency effect by which later perceptions of justice are more influential than initial perceptions.

Lilly et al. (2010) tested a primacy and recency effect in a study that examined changes in individual justice perceptions over time concerning a positive or negative work decision outcome. Their results indicate that perceptions of procedural justice 
may change over time, while perceptions of interpersonal justice do not change over time. Thus, both a primacy and a recency effect were observed in their data for different types of justice. The present study also examines primacy and recency effects in justice, but our definition of justice over time refers to the influence of overall perceptions of justice (initial reference point) on a dependent variable at three time periods. Because the initial reference point originates shortly after a major hurricane, we believe the "honeymoon" period of helping behavior that often occurs after disasters will gradually dissipate. Thus, fairness heuristic theory (Lind 2001) and uncertainty management theory (Lind and Van den Bos 2002; Van den Bos and Lind 2002) are used to develop an argument stating that a recency effect should occur in this particular situation.

Fairness heuristic theory. Fairness heuristic theory (Lind 2001) has been used at least partially to explain longitudinal effects of justice over time (Lilly et al. 2010). Fairness heuristic theory (FHT) focuses primarily on the ability of individuals to use past fairness decisions to develop a heuristic about future decisions. Studies have shown that the fairness heuristic is formed quickly (Van den Bos, Vermunt, and Wilke 1997), and that first impressions of justice influence subsequent perceptions of justice resulting in a primacy effect. FHT does account for phase-shifting events that could cause perceptions of justice to change at a later time, however. For example, when a relationship changes or fairness information becomes known that is contrary to previously formed heuristics, the trust factor that is so important in forming the fairness heuristic may be altered to reflect a new reality of justice perceptions that is different from before resulting in a recency effect. Thus, FHT could support either a primacy or a recency effect in longitudinal justice.

We believe FHT supports a recency effect in the context of our study due to the data collection having occurred in the aftermath of a hurricane. If the problems caused by the hurricane are considered to be uncontrollable by the victims (e.g., loss of power, water, phone service), some researchers suggest that people are more likely to help others (Marjanovic, Struthers, and Greenglass 2012; McManus and Saucier 2012). This implies that a natural disaster could be a phase-shifting event in which perceptions of justice change as former "strangers" at work become more familiar with one another through hurricane stories and sharing (or not sharing) resources to get through the hardship. The uncertainty of the hurricane situation for everyone, along with the potential relationship changes that occur as people actively help one another through the disaster, could alter the previous fairness heuristic to reflect a new reality of justice perceptions. Uncertainty management theory provides additional support for a recency effect. 
Uncertainty management theory. Uncertainty management theory (Lind and Van den Bos 2002; Van den Bos and Lind 2002) suggests that individuals rely on justice judgments most when they are experiencing uncertainty. The theory is built on the idea that fairness, or justice, allows individuals to experience some control over their situation. Seminal works on process control, for example, propose that individuals will accept unfavorable outcomes if they are allowed some control over the process through voice, or reliance on consistent and unbiased procedures (Folger et al. 1979; Greenberg and Folger 1983). When uncertainty is present, individuals use justice judgments to manage their reactions to the situation, and the salience of uncertainty increases the influence of justice perceptions on other aspects of the organization.

Studies using uncertainty management theory have found that mistreatment in an environment of uncertainty amplifies the negative reactions from employees to a larger degree than when mistreatment alone is considered (Tangirala and Alge 2006; Thau, Aquino, and Wittek 2007; Thau, Bennett, Mitchell, and Marrs 2009). Some element of uncertainty is ever-present in most workplaces, and this may be the reason that justice effects are so powerful. In addition, some individuals may experience higher levels of uncertainty than others, and these individuals report stronger negative reactions as well (Thau et al. 2007). For example, an alpha change, which occurs when respondents change their standing on a construct, should occur when levels of uncertainty fluctuate. As uncertainty increases and becomes more salient to an individual, an alpha change in justice perceptions should occur that causes justice perceptions to become more influential. In the context of a natural disaster, as uncertainty about the situation increases or decreases at different time periods, an alpha change in justice perceptions should also occur, and the impact of justice perceptions on a dependent variable at different time periods should change also.

\section{The impact of justice on OCB over time.}

Studies that have specifically examined the effect of justice over time on job attitudes (Ambrose and Cropanzano 2003; Hausknecht et al. 2011; Kim, et al. 2015) have found that temporal changes in justice perceptions are associated with employee attitudes beyond the influence of current justice perceptions. Because the future is almost always uncertain and the present is often uncertain, uncertainty management theory (UMT) supports the premise that perceptions of interpersonal and informational justice should influence constructs such as OCB that are theoretically related to justice at all time periods. 
Few people can predict the future with $100 \%$ accuracy. As a result, uncertainty is ever-present when contemplating future events. UMT suggests this uncertainty of future events will trigger individuals to use fairness heuristics in the present time period to manage their uncertainty about the future. Past events are often certain - that is, they are analyzed and understood so that uncertainty about the past is less salient than uncertainty in the present or the future. Thus, if uncertainty is low or absent, UMT suggests individuals are less likely to use fairness heuristics to manage uncertainty because the uncertainty is already under control. Essentially, UMT supports the idea that past situations or events with no uncertainty will not influence the fairness effect (Folger, et al. 1979; Lind 2001), but situations or events occurring at the present or future time with some level of uncertainty will influence the fairness effect. As a result, we hypothesize there should be a recency effect of justice over time on individual work attitudes and behaviors such that later perceptions of interpersonal or informational justice will be associated with later perceptions of OCB beyond the effect of earlier interpersonal or informational justice perceptions. For example, Time 2 justice perceptions will be associated with time 2 OCB beyond the effect of time 1 justice perceptions, and time 3 justice perceptions will be associated with time 3 OCB beyond the effect of time 1 and time 2 justice perceptions.

H1: There will be a recency effect of justice over time on $O C B$, such that later perceptions of interpersonal (informational) justice will be related to OCB after controlling for previous perceptions of interpersonal (informational) justice.

\section{The Moderating Role of Coping Style}

Research has shown that certain individual characteristics influence how people respond to uncertainty (Gibbons and Buunk 1999; Tobin and Raymundo 2010). In this study, we look at another individual characteristic that could enhance uncertainty - coping style. A number of studies suggest the way individuals cope with stress can impact their reactions to a particular situation. Roth and Cohen (1986) describe two basic categories of coping responses: (a) approach coping, or trying to change the situation by confronting the situation, and (b) avoidance coping, or trying to avoid dealing with the situation.

The coping strategy chosen by the individual depends partly upon the individual's appraisal of the situation. If the appraisal indicates something can be done about the situation, approach coping is dominant. If the appraisal indicates 
nothing can be done about the situation, avoidance coping is dominant (Lazarus 1993, p. 239). Generally speaking, greater approach coping is associated with better psychological outcomes, while greater avoidance coping is associated with poorer psychological outcomes (Holahan and Moos 1990, 1991; Vitaliano, Maiuro, Russo, and Becker 1987).

Researchers in coping often examine the antecedents and consequences of coping to better understand how individual coping style impacts the situation. For instance, some studies have found that fear, anxiety and depression are positively related to avoidance coping (Barker 2007; Duhachek and Oakley 2007; Pakenham 2006), while self-esteem is negatively related to avoidance coping (Barker 2007). Studies examining approach coping have found that anxiety was not significantly related to approach coping (Pakenham 2006). However, anger was positively related to approach coping (Duhachek and Oakley 2007) and feelings of threat were negatively related to approach coping (Scheck and Kinicki 2000). In general, studies on coping report that avoidance, or escapist coping strategies are consistently associated with poor mental health outcomes, while approach coping strategies are sometimes associated with negative outcomes, sometimes positive outcomes, and sometimes neither (Folkman and Moskowitz 2004, p. 747).

UMT states the impact of justice perceptions is most influential in times of uncertainty; thus, the effects of justice on outcome variables such as OCB depend upon the extent to which people perceive the situation as uncertain. Based on the coping literature, it seems reasonable to expect an individual responding to uncertainty using an approach coping style may perceive the situation as less uncertain than an individual responding to uncertainty using an avoidance coping style. This reasoning is based on the premise that individuals engaged in an approach coping style generally will not experience increased fear and anxiety (Duhachek and Oakley 2007; Pakenham 2006), and will approach the situation to resolve it. Indeed, Barclay and Keifer (2014) found that positive emotions, such as being happy and optimistic, significantly mediate the relationship between overall justice and the helping behaviors of altruism and participation. Individuals engaged in approach coping remove some uncertainty simply by acting upon the situation, are likely to be at least somewhat optimistic, and therefore, may rely less on fairness heuristics and more on their own actions and the actions of others to form perceptions of justice.

On the other hand, individuals engaging in an avoidance coping style generally believe nothing can be done about the situation (Lazarus 1993). As a result, fear and anxiety are increased (Barker 2007; Duhachek and Oakley 2007; Pakenham 2006), and avoidance of the situation leaves it unresolved. By choosing not to act upon the 
situation, and allowing it to proceed without resolution, the individual essentially allows uncertainty to continue, and therefore, may rely more on fairness heuristics to form perceptions of justice. Indeed, Barclay and Keifer (2014) found that negative emotions such as being anxious and frustrated significantly mediate the relationship between overall justice and psychological withdrawal.

Although some research in organizational justice suggests a causal relationship between justice and psychological health such that justice impacts psychological health (e.g., Greenberg 2006; Judge and Colquitt 2004), there is some evidence that psychological health influences perceptions of justice. For example, Lang, Bliese, Lang and Adler (2011) found that depressive symptoms influenced subject perceptions of justice three months and six months later in a sample of soldiers deployed on peacekeeping missions or activated in the wake of 9/11. Given this recent finding and the research on coping, we hypothesize that individuals who engage in an avoidance coping style will allow justice perceptions to influence their attitudes and behavior more than individuals who engage in an approach coping style. Coping style will moderate the effects of justice on OCB such that:

H2: There will be a positive moderating effect between perceptions of justice and an avoidance coping style on $O C B$.

H3: There will be a negative moderating effect between perceptions of justice and an approach coping style on $O C B$.

\section{Figure 1. Hypothesized Model.}

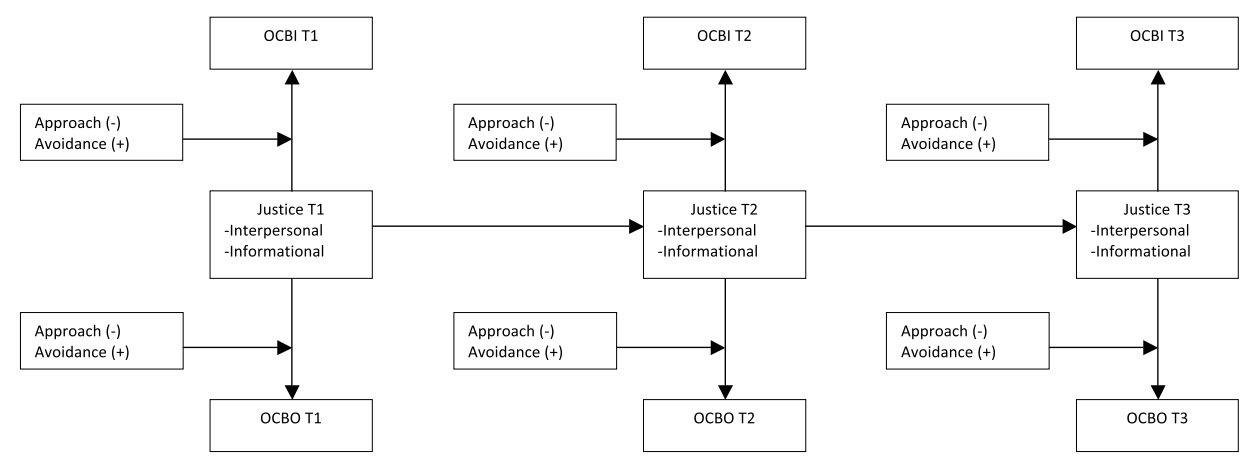

\section{METHOD}

The data for the study were collected after a recent hurricane using a snowball collection method, and the context of a natural disaster allowed us to presume levels of uncertainty existed within the sample. The hurricane also allowed us to presume 
that stress and coping would be a salient issue with respondents, and thus, measures of coping would be particularly relevant.

Students in management classes were given an opportunity to receive extra credit by asking a full-time employee over the age of 30 to complete a series of three surveys about a recent hurricane and their experience in returning to work after the hurricane. Snowball data collection has been used frequently by researchers in recent years (Eaton and Struthers 2002; Jandeska and Kraimer 2005; Rotondo, Carlson, and Kincaid 2003; Treadway, Hochwarter, Kacmar, and Ferris 2005). In a study of hurricane-induced stress, Hochwarter, Laird and Brouer (2008) collected data in one sample by giving undergraduate students course credit for distributing five surveys to full-time employees, similar to our method of asking students after a hurricane to distribute surveys to full time employees over the age of thirty. Because we wished to measure employee attitudes within four weeks of the hurricane, a snowball sample allowed us to meet this deadline. The four week time period was to ensure that uncertainty surrounding the hurricane and its aftermath were not forgotten. Indeed, many people and businesses in a large area surrounding the school were still without power and running water several weeks after the storm.

The cover sheet to the survey was entitled, "Employee reactions to Hurricane Ike," and stated that the purpose of the survey was to learn about individual experiences in returning to work after Hurricane Ike. Participants were thus given an appropriate frame of reference for their responses. The thirty year age requirement was to ensure that respondents were more likely to have a stable job in which uncertainty caused by a hurricane would be a major disruption to their normal work routine. Younger respondents, such as college students who often move from job to job during school, would be less likely to see a major disruption at work since their work schedules are often unstable to begin with.

The hurricane made landfall in the US on September 13, and classes resumed at the university on September 22. The first survey was distributed and completed between October 2 and October 9; the second survey was distributed and completed between November 4 and November 11; and the third survey was distributed and completed between December 2 and December 9. Out of a total of 324 questionnaires distributed, 255 were returned, yielding the response rate of $78.7 \%$. After screening for missing data, we eliminated 42 responses, resulting in a final sample size of 213. Respondents were from 14 different industries. Average age was 43.35, and approximately $49 \%$ were men and $45.5 \%$ were women (5.5\% did not respond). All had been affected by the hurricane, although only $1.2 \%$ reported that either they or one of their family members suffered from actual physical injury as a result of 
the hurricane. Many lost power (86.7\%), with 39.9\% reporting they were without electricity for over six days. Although $35.2 \%$ of the respondents returned to work two days after the storm, 23.9\% did not return to work until after September 19, seven days after the storm hit. The other $40.9 \%$ of respondents returned to work somewhere between three days and six days after the storm, with $12.5 \%$ returning after three days, $15.7 \%$ after four days, $8.3 \%$ after five days, and $4.4 \%$ after six days. In December, $31 \%$ of the respondents reported that people were still talking about the hurricane at work three months later.

\section{Measures}

All variables were measured using either a 7-point or a 5-point Likert scale. For the organizational behavior scales and the coping scales, the items asked how often respondents engaged in certain behavior or how often they reacted a certain way to stress episodes. The response format for these two scales was, $1=$ never and $7=$ always. The justice scales asked respondents to what extent supervisors engaged in certain behaviors. Following the example of Colquitt (2001), these items used a 5 -point scale with $1=$ to a very small extent and $5=$ to a very large extent.

Coping response. Items measuring coping response strategies were measured at time 1 and were taken from the coping response inventory (Moos, 1993). Coping strategies are categorized into two main dimensions - (a) approach or avoidance and (b) cognitive or behavioral. For approach coping strategies, we used two subscales: positive reappraisal (a cognitive strategy) and problem solving (a behavioral strategy). For avoidance coping strategies, we used the following two subscales: cognitive avoidance (a cognitive strategy) and emotional discharge (a behavioral strategy). These four subscales were used by Valentiner, Holahan, and Moos (1994) as representatives of approach and avoidance coping; thus, we follow their example and do the same in the present study. Each subscale consisted of 6 items, and sample items include the following: "Try not to think about the problem" (cognitive avoidance); "Yell or shout to let off steam" (emotional discharge); "Make a plan of action and follow it" (problem solving); and "Try to see the good side of the situation" (positive reappraisal). The cognitive avoidance and emotional discharge scales were added together to get one score for the avoidance coping and the problem solving and positive reappraisal scales were added together to get one score for the approach coping scale.

Justice. The items for interpersonal justice and informational justice were measured at all three time periods and were taken from Colquitt's (2001) scale. 
Interpersonal justice was measured with four items, and informational justice was measured with five items. Sample items include, "To what extent does your supervisor treat you in a polite manner" (interpersonal justice), and "To what extent does your supervisor explain work procedures thoroughly at work" (informational justice).

Organizational citizenship behavior (OCB). Sixteen items were used to measure OCB, with eight items representing OCB directed toward the individual (OCBI) and eight items representing OCB directed toward the organization (OCBO). These items were measured at all three time periods and were taken from Lee and Allen's (2002) scale. Respondents were asked how often they engaged in behaviors such as "Share personal property with others to help their work" (OCBI) and "Take action to protect the organization from potential problems" (OCBO).

\section{RESULTS}

We used SmartPLS 2.0 M3 (Ringle, Wende, and Will 2005) to analyze the measurement and structural models. Unlike a covariance-based structural equation modeling (SEM) used in LISREL, Partial Least Squares (PLS), a component-based SEM, was chosen because it is more flexible in terms of both distribution assumptions (e.g. multivariate normality is not necessary) and sample size requirements (Chin, Marcolin, and Newsted 2003). Considering the purpose of the study and the ratio between the number of the constructs in the models and the sample size, we believed that using PLS would be a more appropriate choice.

\section{Measurement Model}

We validated psychometric properties (i.e., discriminant validity, convergent validity, and reliability) of the constructs using SmartPLS. As a result of the first run, using 0.6 as a cutoff value, we eliminated six items of the approach construct ( 3 items from positive reappraisal and 3 items from problem solving) and six items of the avoidance construct ( 3 items from cognitive avoidance and 3 items from emotional discharge). It is not uncommon to have low internal consistency in coping scales, because using one coping response could reduce the need to use other responses from the same category (Holahan, Moos, Holahan, and Brennan 1997; Moos and Holahan 2003; Timko, Cronkite, and Moos 2010). Indeed, in a study of stressors and avoidance coping, Timko et al. (2010) created an avoidance coping scale by combining two items of a cognitive nature with six items of a behavioral nature. Our scales thus combine three cognitive items and three behavioral items for both the 
approach coping style and the avoidance coping style.

Noticeably, the results of the subsequent run improved, in that they attested discriminant validity, convergent validity, and reliability of all the constructs as described below. As shown in Table 1, the square root of the average variance extracted (AVE) of each of the constructs was greater than its correlation with all the other constructs, thus demonstrating discriminant validity (Gefen and Straub 2005). In addition, while there were still some cross-loading items between those of informational justice and those of interpersonal justice, we decided to retain the items, because not only were the differences of the loadings very small (from 0.10.3 ), they also had been well validated by previous researchers (e.g., Colquitt 2001). Furthermore, the majority of the items in fact reasonably loaded $(>0.6)$ on their own factors (see Table 2), showing evidence of discriminant validity (Gefen and Straub 2005). The t-statistics of all the items loading on their respective factors (ranging from 7.48 to 123.2 ) were significant at the 0.001 level, strongly exhibiting a high degree of convergent validity (Gefen and Straub 2005). Finally, both composite reliability and Cronbach's alpha coefficients of all the constructs exceeded 0.8, indicating satisfactory reliability (Fornell and Larcker 1981; Nunnally 1978). Taken together, these results demonstrated the quality of the measurement model. Thus, we then turned to examine the structural model. 


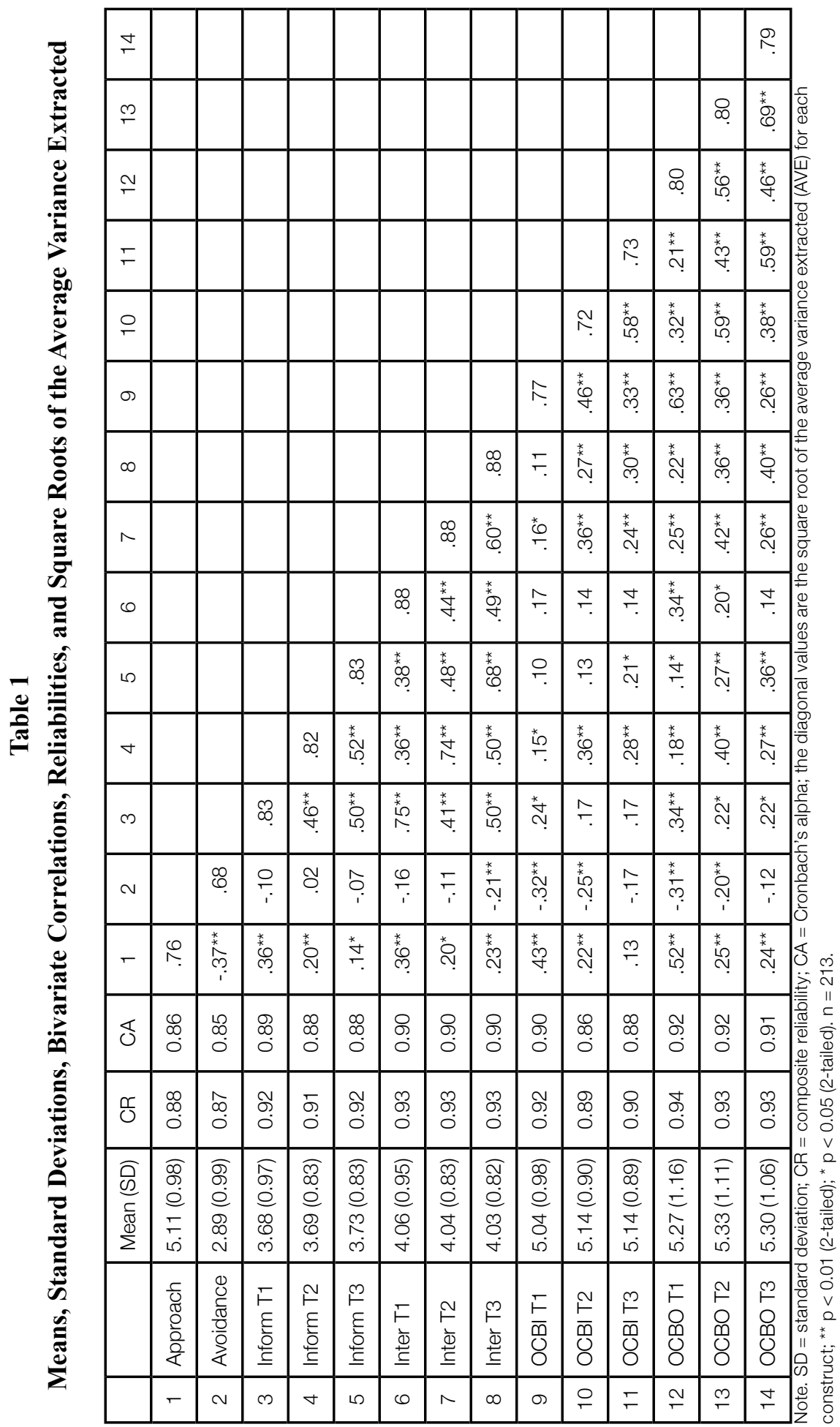




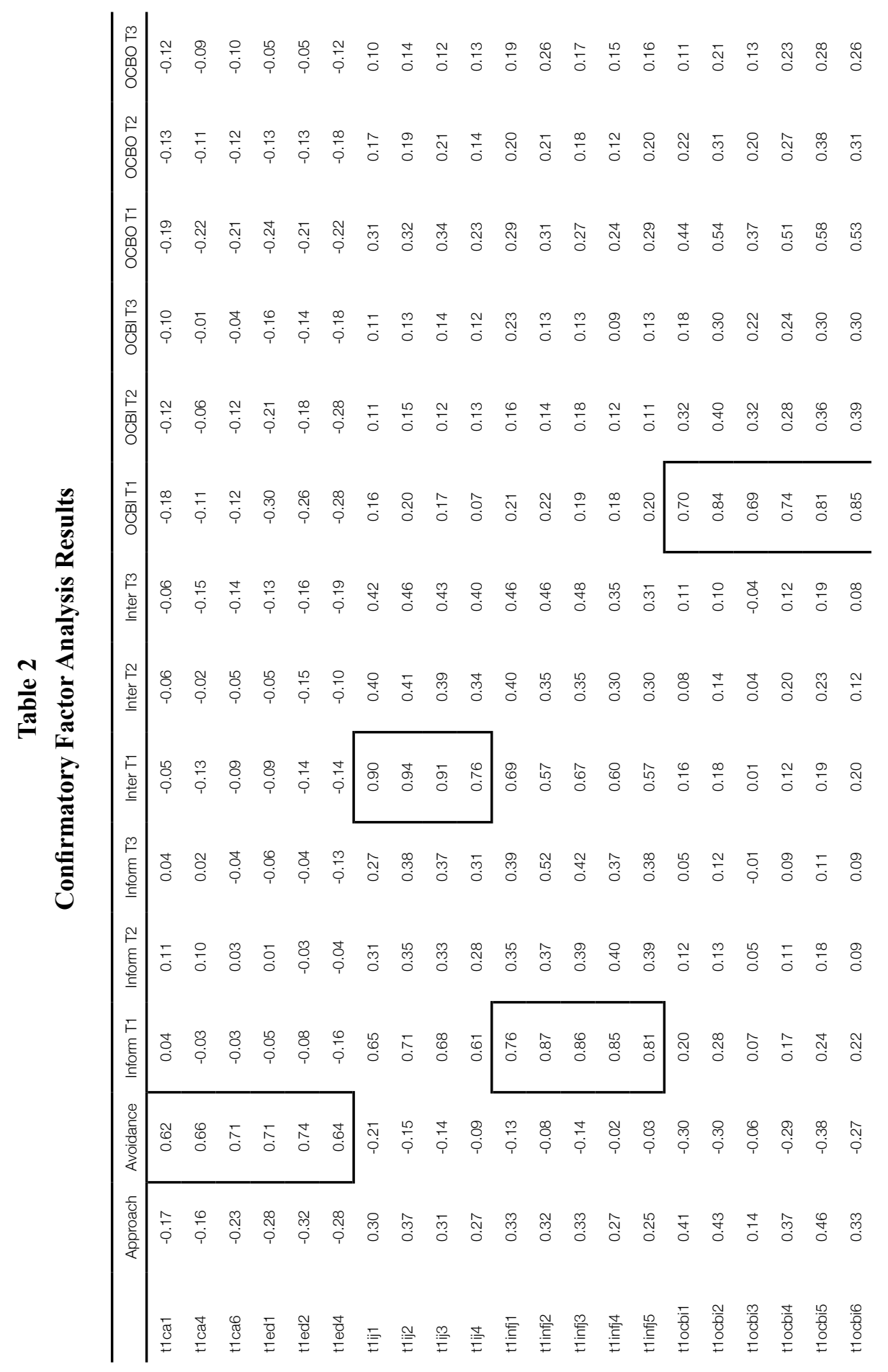




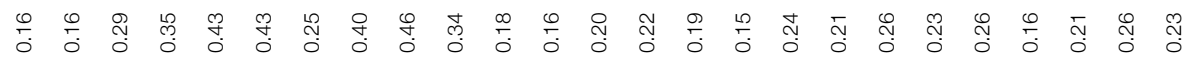

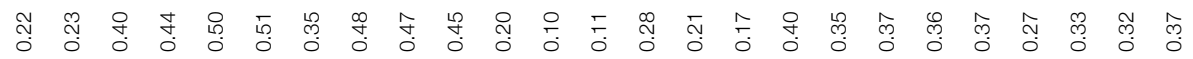
苟

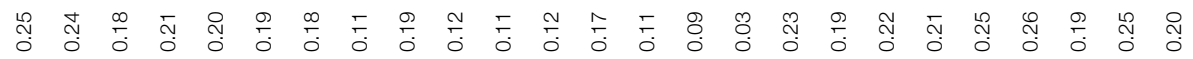

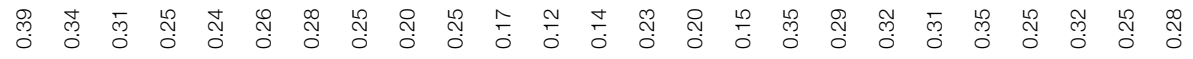

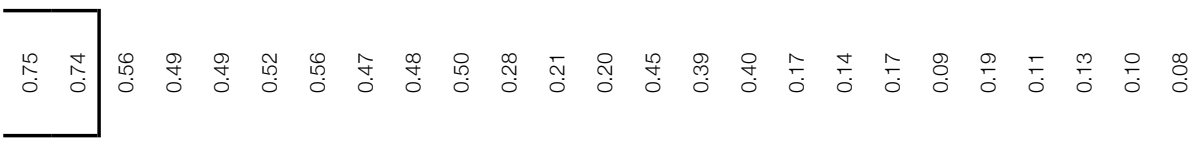
官

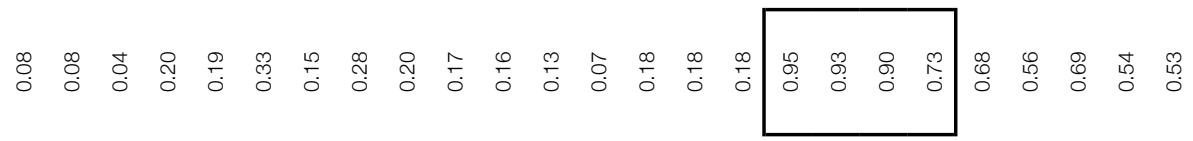

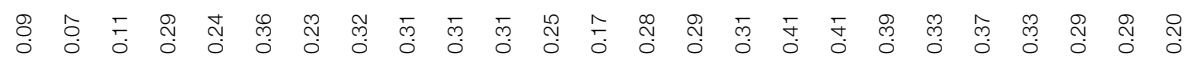

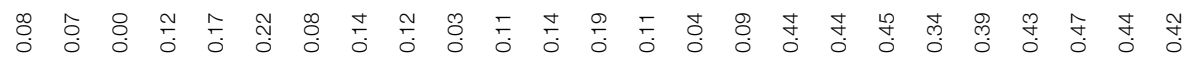

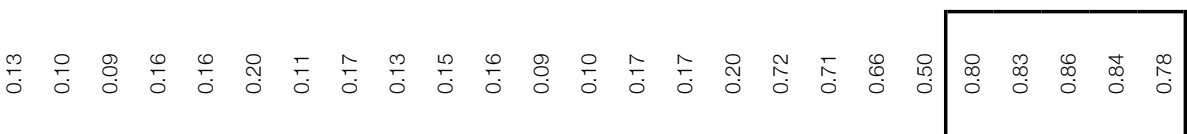

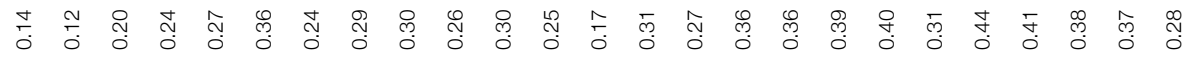

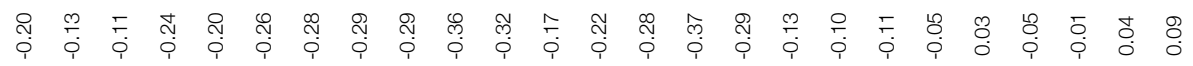

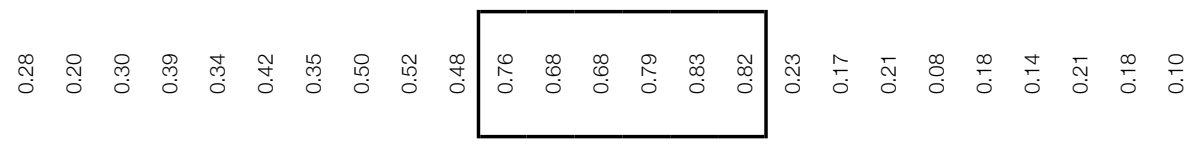

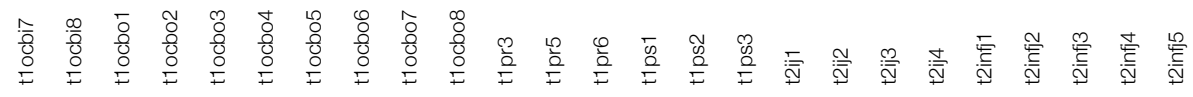




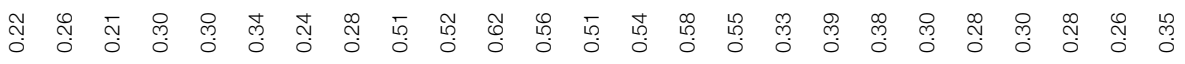

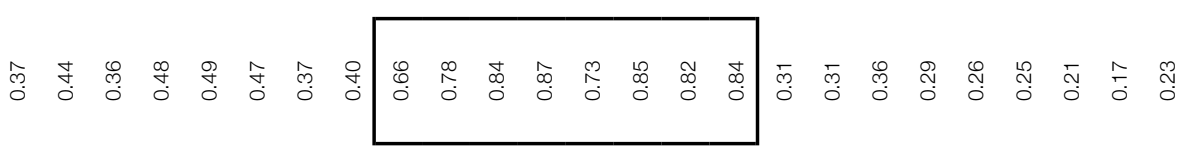

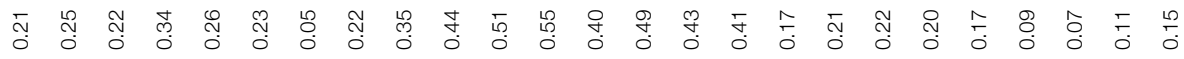

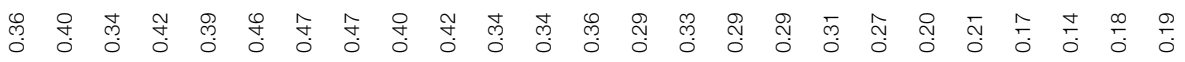

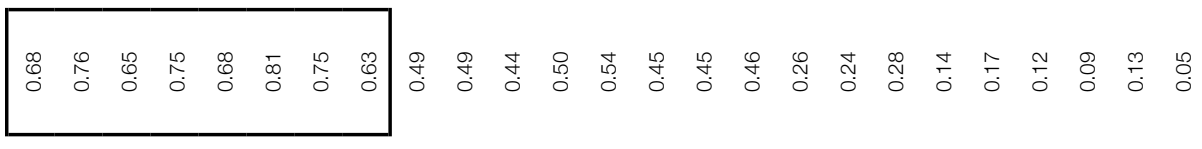

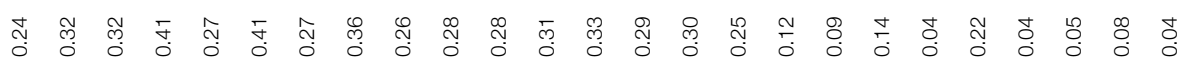

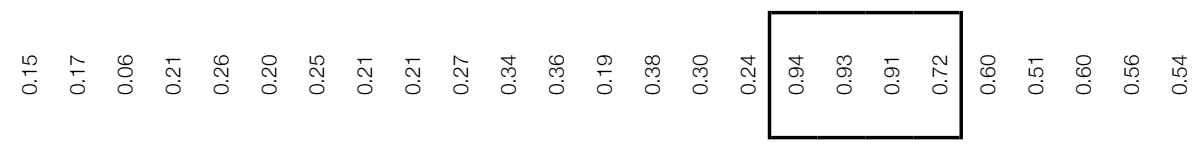

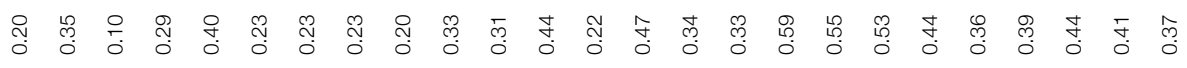

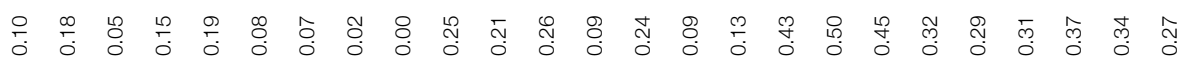

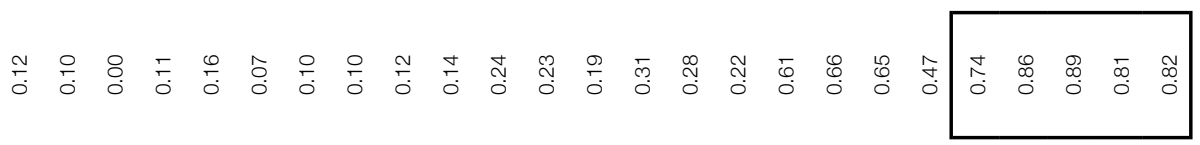

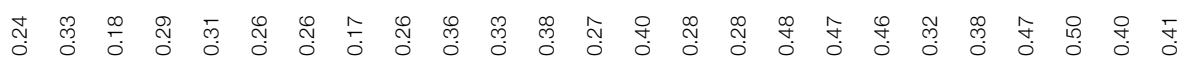

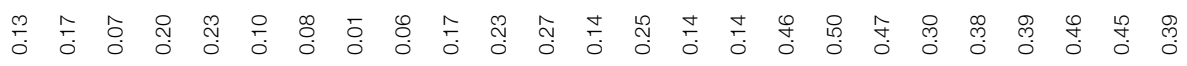

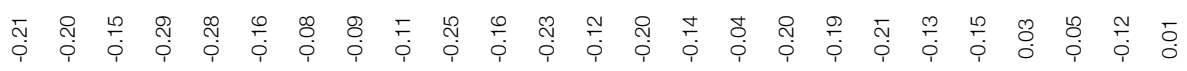
舟

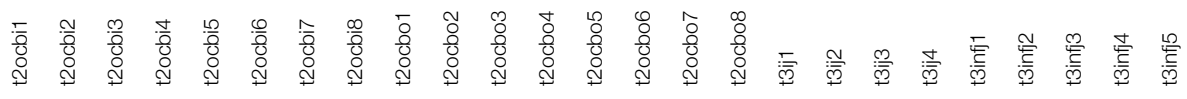




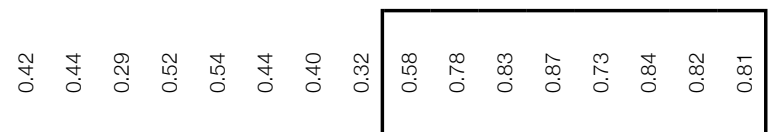

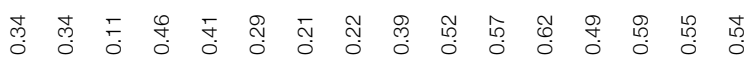

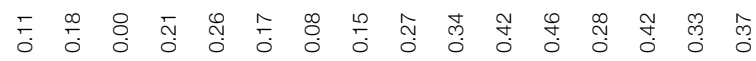

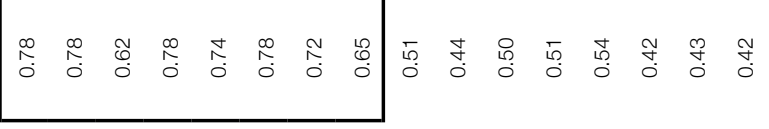

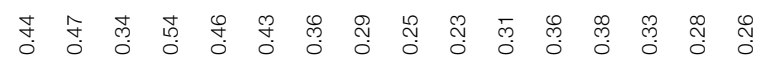
每 年

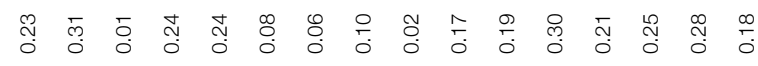
帘 糸

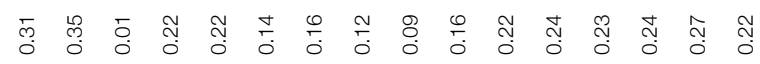
苟 突

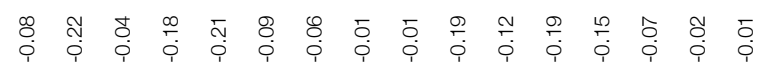
告

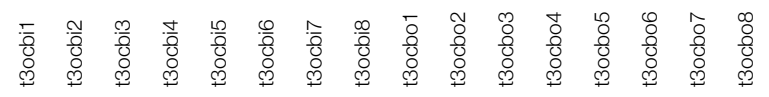




\section{Structural Model}

To examine the significance of the paths in SmartPLS, we performed a bootstrapping procedure ( $\mathrm{n}=213$ with 500 samples). Running one model for interpersonal justice and another separate model for informational justice, we found the results appeared to be somewhat similar. In the PLS models, we controlled the effects of justice and OCB over time by linking those at earlier times to those at later times; for example, OCBI and OCBO T1 was linked to OCBI T2, OCBO T2, OCBI T3, and OCBO T3; justice T1 was linked to OCBI T2, OCBO T2, OCBI T3, and OCBO T3; justice T2 was linked to OCBI T3 and OCBO T3. The moderating terms were generated using an algorithm demonstrated in the work of Chin et al. (2003).

The first hypothesis states that there will be a recency effect of justice over time on OCB, such that later perceptions of justice will be related to OCB after controlling for previous perceptions of justice. To test this hypothesis, we examined the beta coefficients and $p$-values between justice at each time period and OCB at each time period. If the beta coefficients between justice and OCB have greater significance (lower $p$-values) at later time periods than in earlier time periods, there is evidence of an incremental effect of justice over time on OCB, suggesting a possible recency effect triggered by uncertainty. Additionally, there is evidence of an incremental effect of justice over time if the beta coefficients between justice and OCB are significant at later time periods, but not significant at earlier time periods. For example, if the beta coefficient between justice at time 1 and OCB at time 2 is not significant, but the beta coefficient between justice at time 2 and OCB at time 2 is significant, there is evidence that time 2 justice perceptions are associated with OCB at time 2 beyond the effects of time 1 justice perceptions. ${ }^{1}$

\section{Relation Between Interpersonal Justice and OCB.}

Regarding interpersonal justice (see Figure 2), interpersonal justice at time 1 overall explained about $19 \%$ of the variance in interpersonal justice at time 2 , and accounting for the effect of time 1, interpersonal justice at time 2 overall explained about $36 \%$ of the variance in interpersonal justice at time 3 . At time 1 , interestingly, none of the relationships were significant except for the direct relationship between interpersonal justice and OCBO $(b=.17, \mathrm{p}<.001)$. 
Figure 2. Results of Path Analysis for Interpersonal Justice.

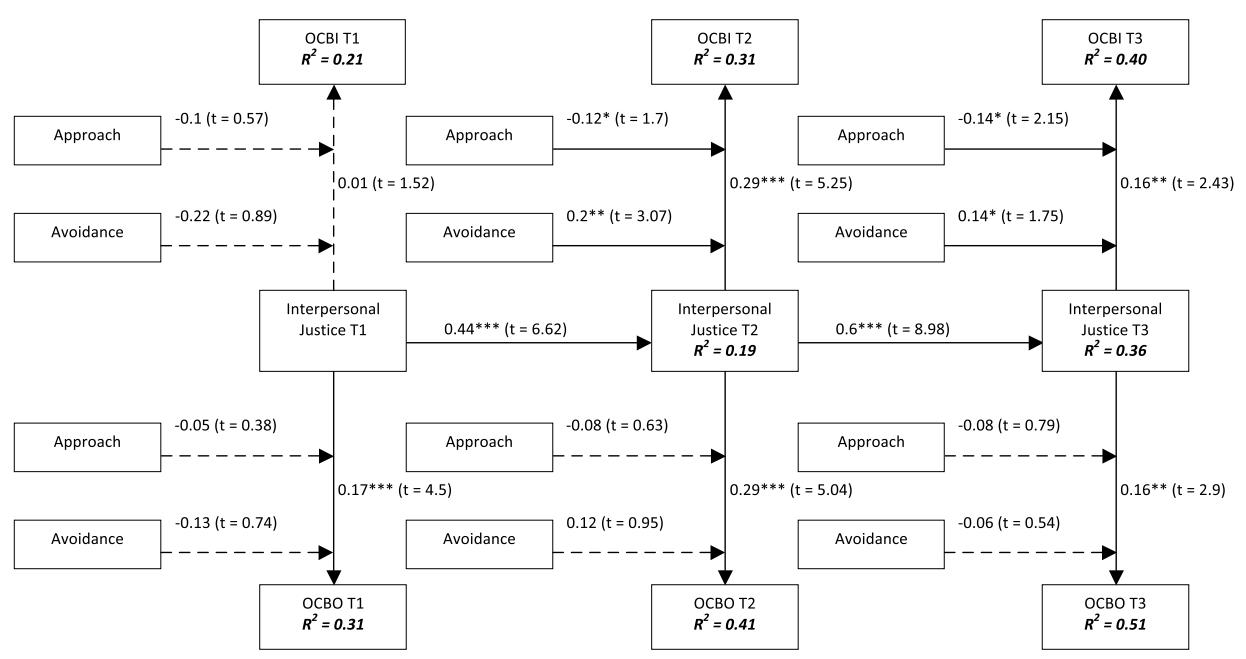

Note: ${ }^{\star} \boldsymbol{p}<0.05,{ }^{\star \star} \boldsymbol{p}<0.01,{ }^{\star \star \star} \boldsymbol{p}<0.001$ in one-tailed tests.

Dashed line represents insignificant path. This figure has been simplified from the model run in SmartPLS e.g. the paths of OCBI and OCBO from earlier to later times, as control variables, are not shown for clarity.

At time 2, interpersonal justice was found to be a significant predictor of both OCBI $(b=.29, p<.001)$ and OCBO $(b=.29, p<.001)$. Comparing this result to the relationship between interpersonal justice at time 1 and OCB at time 2 , we found that interpersonal justice at time 1 was not a significant predictor of OCBI at time $2(b=-.1, n s)$, but was a significant predictor of OCBO at time $2(b=-.12, p<$ $.05)$. Since the $\mathrm{p}$-value is not significant for OCBI and is weaker for OCBO $(p<.05$ versus $p<.001$ ), this indicates the effects of interpersonal justice at time 2 on OCB at time 2 are greater than the effects of interpersonal justice at time 1 on OCB at time 2, supporting hypothesis 1 .

At time 3, interpersonal justice was also found to be a significant predictor of both OCBI time $3(b=.16, p<.01)$ and OCBO time $3(b=.16, p<.01)$, while the relationship between interpersonal justice at time 2 and OCB at time 3 were insignificant ( $b=-.13, n s$ for OCBI; $b=-.15, n s$ for OCBO). This again indicates a recency effect of justice over time on OCB in support of hypothesis 1.

Relation between informational justice and $\mathrm{OCB}$. Regarding informational justice (see Figure 3), we found that informational justice at time 1 overall explained about $21 \%$ of the variance in informational justice at time 2 , and accounting for the 
effect of time 1, informational justice at time 2 overall explained about $27 \%$ of the variance in interpersonal justice at time 3 . At time 1 , informational justice was found to be a significant predictor of both OCBI $(b=.2, p<.001)$ and OCBO $(b=.3, p<$ $.001)$.

Figure 3. Results of Path Analysis for Informational Justice.

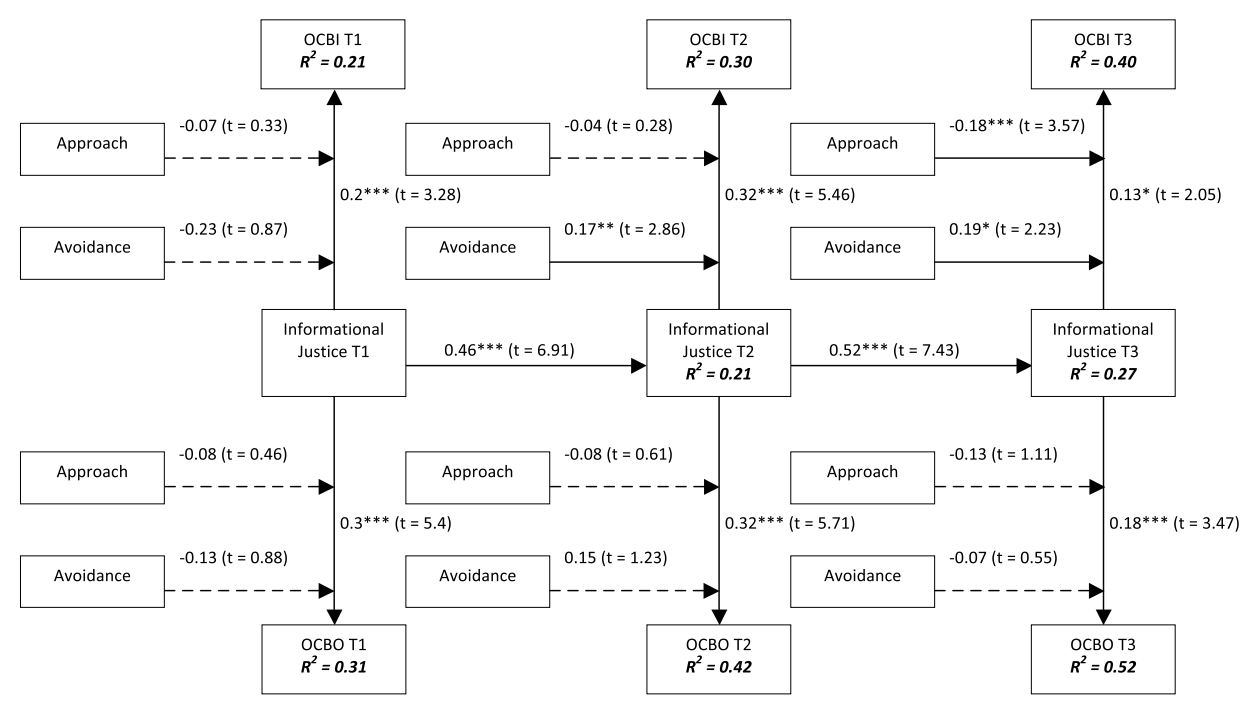

Note: ${ }^{\star} p<0.05,{ }^{\star \star} p<0.01,{ }^{\star \star *} p<0.001$ in one-tailed tests.

Dashed line represents insignificant path. This figure has been simplified from the model run in SmartPLS e.g. the paths of OCBI and OCBO from earlier to later times, as control variables, are not shown for clarity.

At time 2, informational justice was also found to be a significant predictor of both OCBI $(b=.32, p<.001)$ and OCBO $(b=.32, p<.001)$. Comparing this result to the relationship between informational justice at time 1 and OCB at time 2 , we found that informational justice at time 1 was not a significant predictor of OCBI at time $2(b=-.1, n s)$, but was a significant predictor of OCBO at time $2(b=-.13, p<$ $.05)$. Since the $p$-value is not significant for OCBI and is weaker for OCBO $(p<.05$ versus $p<.001$ ), this indicates the effects of informational justice at time 2 on OCB at time 2 are greater than the effects of informational justice at time 1 on OCB at time 2, supporting hypothesis 1 .

Finally, at time 3, informational justice was found to be a significant predictor of both OCBI $(b=.13, p<.05)$ and OCBO $(b=.18, p<.001)$. Comparing this result to the relationship between informational justice at time 2 and OCB at time 3 , we 
found that informational justice at time 2 was not a significant predictor of OCBI at time $3(b=.01, n s)$, but was a significant predictor of OCBO at time $3(b=-.13$, $p<.05)$. Again, the comparison shows either a non-significant result for OCBI or a weaker significance value for OCBO $(p<.05$ versus $p<.001)$, indicating support for hypothesis 1 .

Avoidance coping as a moderator. Hypothesis 2 stated there would be a positive moderating effect between perceptions of justice and an avoidance coping style on OCB. The interaction terms were generated in SmartPLS, using an algorithm in line with the interaction approach demonstrated in the work of Chin et al. (2003), and the hypothesis was tested at each time period. As seen in Figure 2, there was no interaction effect between perceptions of interpersonal justice and avoidance on OCB at time $1(b=-.22, n s$ for OCBI; $b=-0.13, n s$ for OCBO). However, at time 2 , there was a positive interaction between interpersonal justice and avoidance on OCBI at time $2(b=.2, p<.01)$, but not on OCBO at time $2(b=.12, n s)$. There was also a positive interaction between interpersonal justice and avoidance at time 3 on OCBI time $3(b=.14, p<.05)$, but not on OCBO time $3(b=-.06, n s)$.

The results for informational justice found similar results as shown in Figure 3. There was no interaction between perceptions of informational justice and avoidance at time $1(b=-.23, n s$ for OCBI; $b=-.13, n s$ for OCBO), but there was a positive interaction between perceptions of informational justice time 2 and avoidance on OCBI time $2(b=.17, p<.01)$ and no interaction on OCBO time $2(b$ $=.15, n s)$. At time 3 , there was a positive interaction between informational justice and avoidance on OCBI at time $3(b=.19, p<.05)$, but not on OCBO at time 3 ( $b$ $=-.07, n s)$.

Approach coping as a moderator. Hypothesis 3 stated there would be a negative moderating effect between perceptions of justice and an approach coping style on OCB. The hypothesis was tested in each time period. As shown in Figure 2 , there was no interaction effect between perceptions of interpersonal justice and approach on OCB at time 1 ( $b=-.1, n s$ for OCBI; $b=-.05, n s$ for OCBO). At time 2, there was a negative interaction between interpersonal justice time 2 and approach on OCBI at time $2(b=-.12, p<.05)$, but not on OCBO at time $2(b=-.08, n s)$. At time 3 , there was a negative interaction between interpersonal justice time 3 and approach on OCBI at time $3(b=-.14, p<.05)$, but not on OCBO at time $3(b=-.08$, $n s)$. 
For informational justice shown in Figure 3, there was no significant interaction between informational justice and approach on OCB at time $1(b=-.07$, ns for OCBI time $1 ; b=-.08, n s$ for OCBO time 1$)$ nor at time $2(b=-.04, n s$ for OCBI; $b=-.08$. $n s$ for OCBO). At time 3 , there was a significant interaction between informational justice time 3 and approach on OCBI time $3(b=-.18, p<.001)$, but not on OCBO time $3(b=-.13 n s)$.

Comparing the findings on interpersonal and informational justice, we found that the results appeared to be rather similar, except that: At time 1, while the relationship between interpersonal justice and OCBI was not significant, the relationship between informational justice and OCBI was strongly significant. At time 2, while the relationship between interpersonal justice and OCBI was negatively moderated by approach coping style, the relationship between informational justice and OCBI was not.

Nature of the significant interaction effects. To illustrate the nature of the significant interaction effects, we plotted the relationship between coping styles and OCBI at a high and low level of both interpersonal and informational justice (i.e. the mean \pm SD) (see Figure 4-Figure 7). The plots of the interaction effects between interpersonal justice and approach on OCBI at both time 2 and time 3 indicated that the positive relationship between interpersonal justice and OCBI was weaker when approach was high than when it was low (see Figure 4A and 5A), thus confirming that approach negatively moderated the relationship at both times. This finding was even more prominent on the relationship between informational justice and OCBI at time 3 (see Figure 7A). On the other hand, both the relationship between interpersonal justice and OCBI and the relationship between informational justice and OCBI at both time 2 and time 3 were much stronger when avoidance was high than when it was low (see Figure 4B, 5B, 6B, and 7B), therefore confirming that avoidance positively moderated such a relationship at both times. 


\section{Figure 4. Plots of Significant Interaction Effects Between Interpersonal Justice T2 and Coping Styles on OCBI T2.}

(4A) Interaction Effect between Interpersonal Justice T2 and Approach on OCBIT2

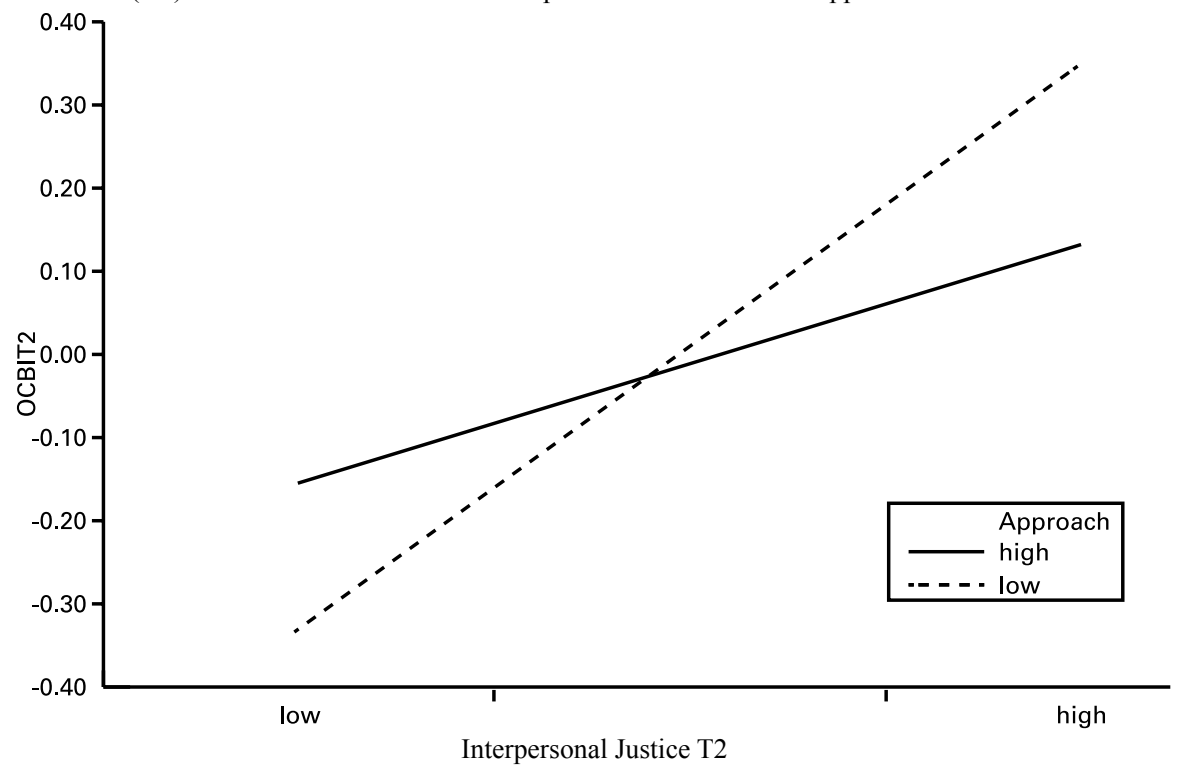

(4B) Interaction Effect between Interpersonal Justice T2 and Avoidance on OCBIT2

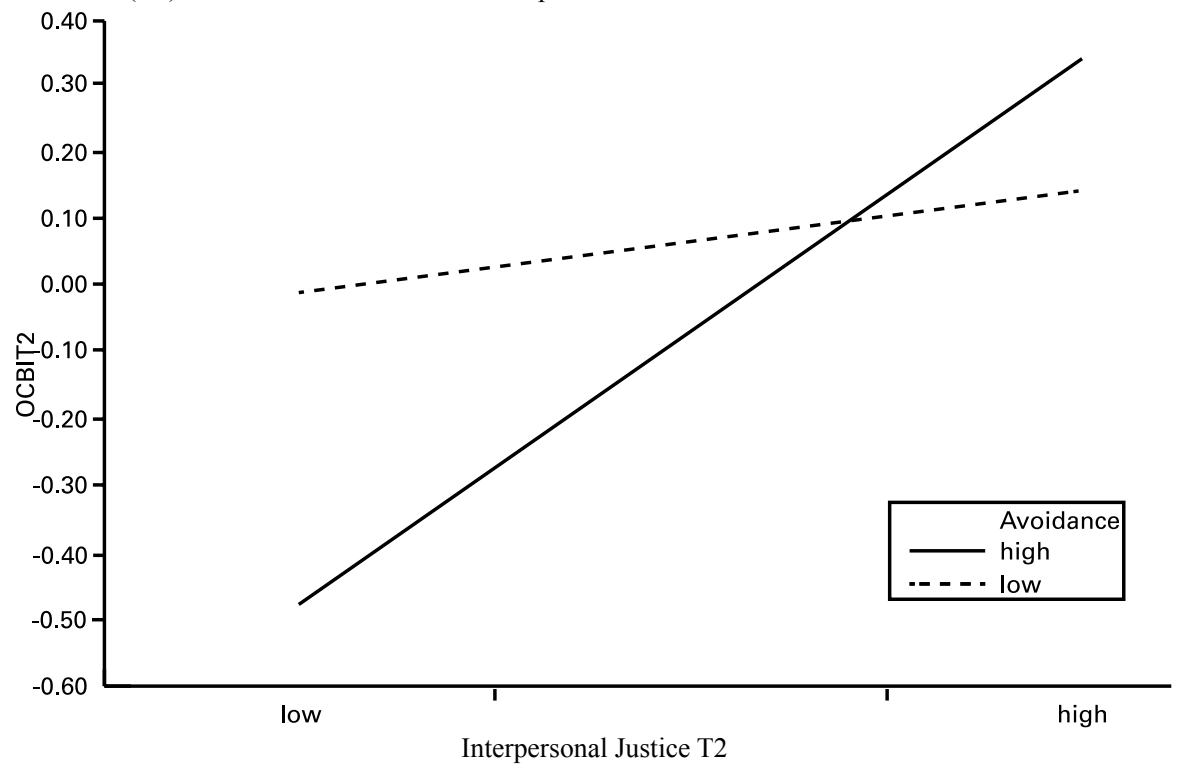


Figure 5. Plots of Significant Interaction Effects Between Interpersonal Justice T3 and Coping Styles on OCBI T3

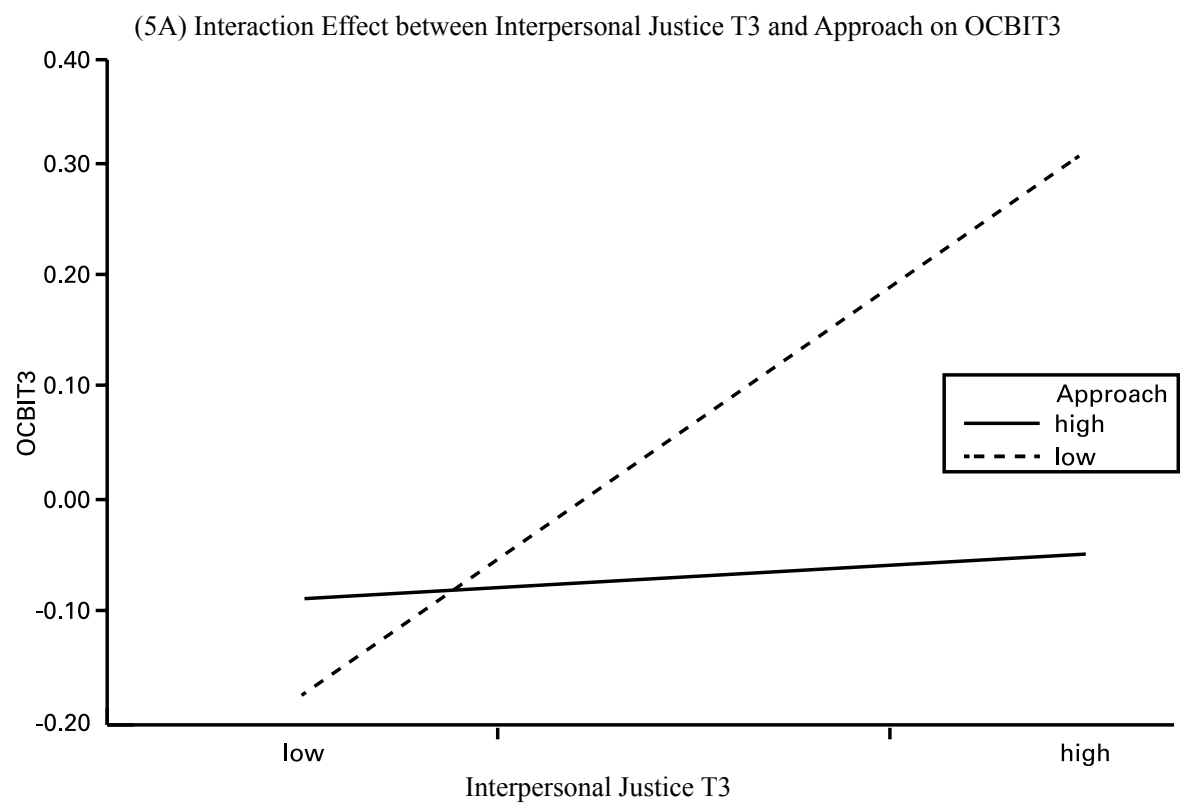

(5B) Interaction Effect between Interpersonal Justice T3 and Avoidance on OCBIT3

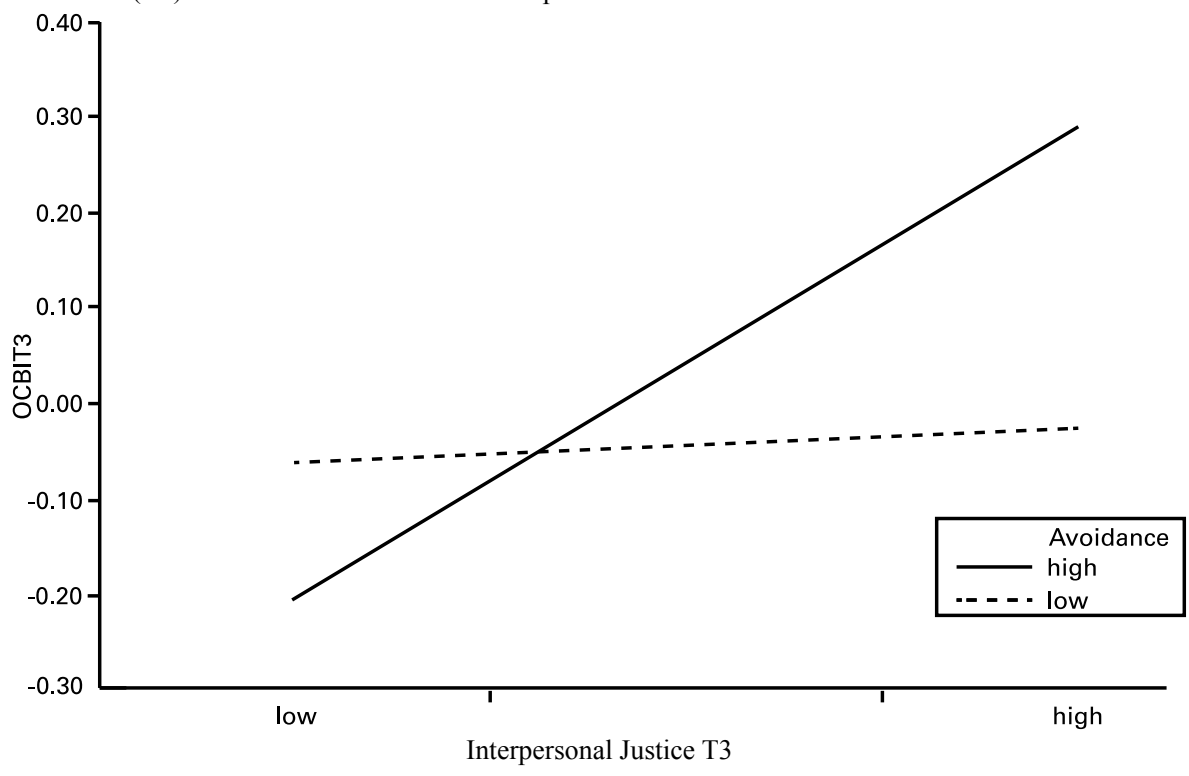


Figure 6. Plot of Significant Interaction Effect Between

Informational Justice T2 and Avoidance Coping Style on OCBI T2.

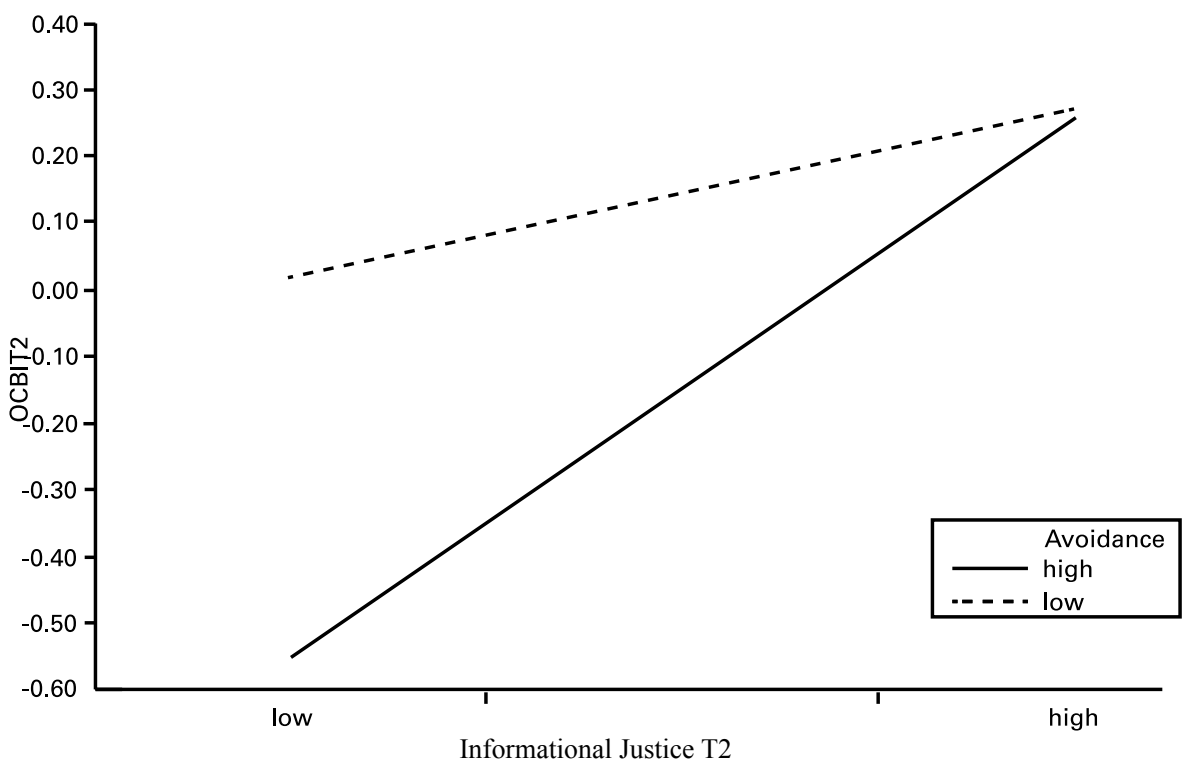

Figure 7. Plots of Significant Interaction Effects Between Informational Justice T3 and Coping Styles on OCBI T3.

(7A) Interaction Effect between Informational Justice T3 and Approach on OCBIT3

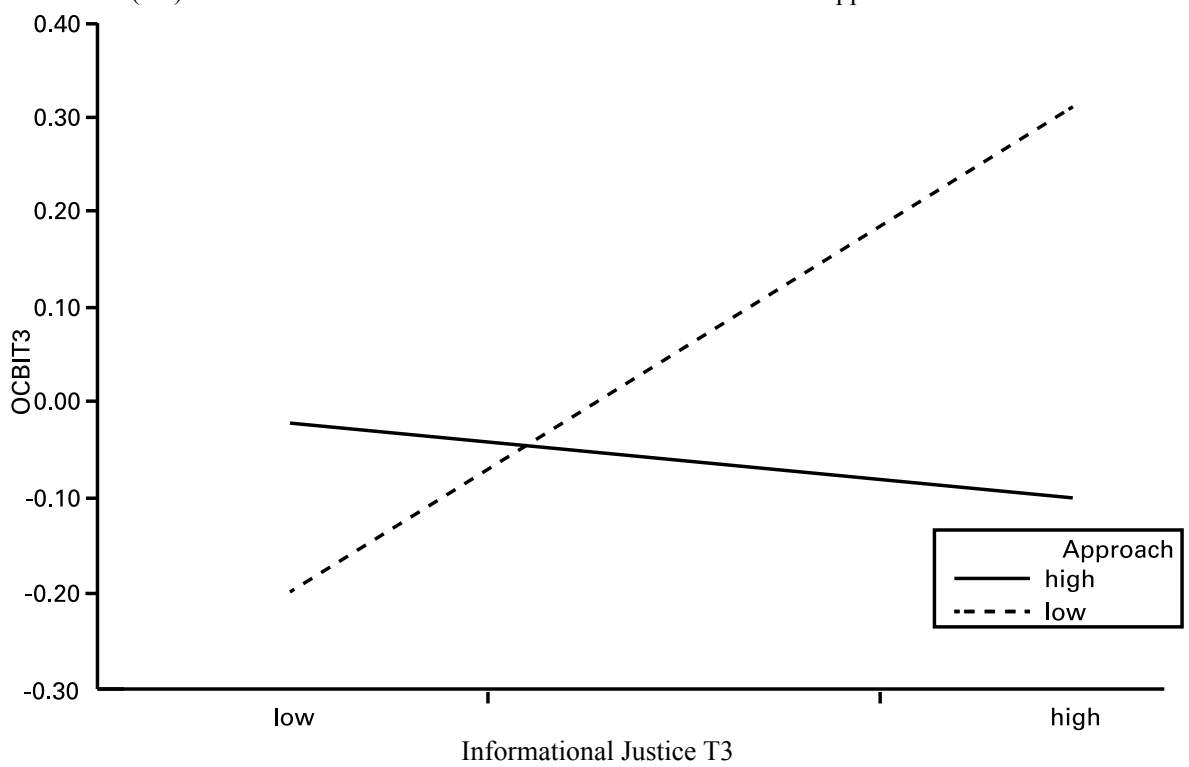




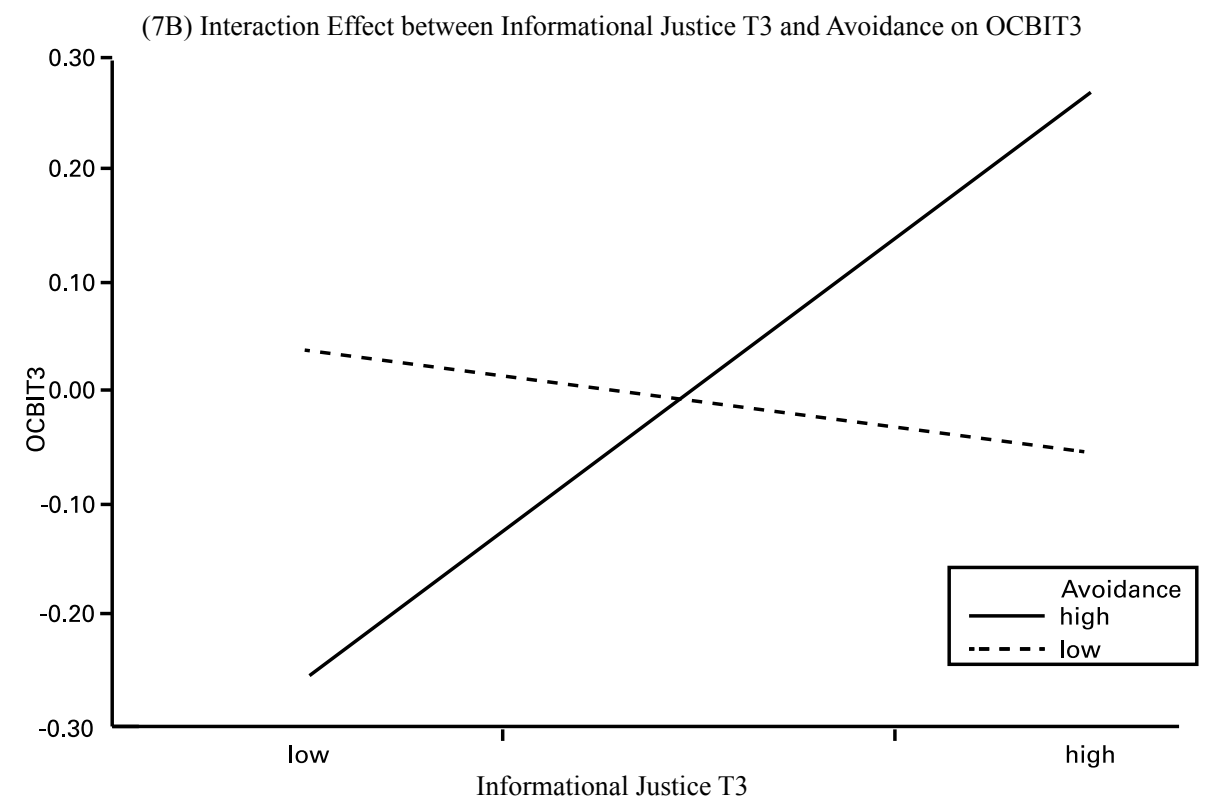

\section{Common Method Variance}

To examine whether common method variance biased our findings, we performed Harman's single-factor test by using principal component analysis, both unrotated and rotated with varimax rotation, with all the items for avoidance, approach, OCBI, OCBO, interpersonal justice and informational justice at different times (Podsakoff et al. 2003). We found that the first factor explained merely about $30 \%$ of the total variance of $66 \%$ at time 1 , about $27 \%$ of the total variance of $68 \%$ at time 2 , and about $25 \%$ of the total variance of $66 \%$ at time 3 . Thus, this result suggested that no general factor accounting for the majority of the covariance in the variables existed and that common method variance was unlikely to confound the findings.

\section{DISCUSSION}

The first hypothesis stating there will be a recency effect of justice over time on OCB was supported. We believe uncertainty management theory and fairness heuristic theory help explain this finding because uncertainty in current time periods should be more prevalent or salient than uncertainty in past time periods. Presumably, some issues with uncertainty are resolved as time progresses and more information becomes available to individuals allowing them to better understand the past. Because of this, perceptions of justice in the current time period with higher levels 
of uncertainty were more influential in the current time period than perceptions of justice in past time periods. This finding is similar to that found by Holtz and Harold (2009) and Lilly et al. (2010), but contradicts the findings reported by Hausknecht et al. (2011). While the Holtz and Harold (2009) and Lilly et al. (2010) studies suggest a recency effect occurs due to within-person changes over time, Hausknecht et al. (2011) suggest that a primacy effect may occur such that perceptions of justice are formed through a series of experiences over time, thus forming a fairness heuristic that acts as a template for evaluating future judgments. We believe the context of uncertainty due to disruptions at work and at home may have created a phase-shifting event in which fairness heuristics were re-formed. Rather than using a fairness heuristic template formed by past events that would indicate a primacy effect in justice perceptions, individuals re-formed fairness heuristics at each time period based on the uncertainty at that time period, indicating a recency effect in justice perceptions.

Experimental studies on uncertainty management theory have found that when uncertainty was made salient, justice manipulations were stronger than when uncertainty was not salient (Van den Bos 2001; Van den Bos and Miedema 2000). Essentially, any kind of uncertainty can boost the influence of justice, not just uncertainty in the workplace. Indeed, one study in support of uncertainty management theory created feelings of uncertainty by asking participants to consider their feelings about death (Van den Bos and Miedema 2000). Because uncertainty appears to be influential in forming justice perceptions, the context of a natural disaster used in the present study allowed us to take advantage of uncertainty in two different contexts - at home, and at work. We believe the uncertainty created by a natural disaster increased the influence of justice perceptions as described by uncertainty management theory and fairness heuristic theory. Indicators of uncertainty felt by respondents included the following facts: many participants (39.9\%) reported losing power for over six days; $23.9 \%$ reported not returning to work for six days; and $31 \%$ of respondents reported that people at work were still talking about the hurricane three months later. Cleanup in the state of Texas was still not complete after six months, and the cleanup effort affected both homeowners and organizations in Texas (FEMA, Aug 11, 2010). Thus, at each time period, respondents as a whole were not "finished" with the hurricane; therefore, uncertainty at each time period could have caused perceptions of justice in the current time period to be more influential than past perceptions of justice. 
The high level of uncertainty felt by the general population should have created a context in which justice perceptions become more salient; however, individual reactions to uncertainty may also influence perceptions of justice or individual behavior. Thus, the premise of hypotheses 2 and 3 take into account individual reactions to stressful situations, which could increase or mitigate feelings of uncertainty.

The second hypothesis stated there will be a positive moderating effect between perceptions of justice and an avoidance coping style on OCB. Prior literature on coping suggests that fear, anxiety and depression are positively related to avoidance coping (Barker 2007; Duhachek and Oakley 2007; Pakenham 2006). In addition, individuals engaging in an avoidance coping style generally believe nothing can be done about the situation (Lazarus 1993). We argue the combination of fear, anxiety, depression, and the belief that nothing can be done creates a condition in which individuals will allow the situation to continue without resolution, essentially prolonging any uncertainty that exists. Thus, individuals engaged in avoidance coping may be more likely to rely on fairness heuristics to form perceptions of justice, meaning that justice perceptions become more influential in determining future behavior and perceptions of organizational variables. Hypothesis 2 was supported for OCBI, but not for OCBO.

The third hypothesis stated there will be a negative moderating effect between perceptions of justice and an approach coping style on OCB. This hypothesis is based on literature stating that individuals engaged in an approach coping style generally will not experience increased fear and anxiety (Duhachek and Oakley 2007; Pakenham 2006). Thus, these individuals will approach the situation to resolve it. By acting upon the situation, individuals are removing some of the uncertainty and may be less likely to rely on fairness heuristics to form justice perceptions, meaning that justice perceptions become less influential in determining future behavior and perceptions of organizational variables. Hypothesis 3 was supported for OCBI at time 3 for interpersonal justice and informational justice, but only for OCBI at time 2 for interpersonal justice.

The finding that coping style is a significant moderator only for OCBI, and not for OCBO, indicates that coping style and justice perceptions may be more influential at the individual level and less influential at the organizational level. The reason for this finding may be due to the context of the study, a natural disaster. Natural disasters are experienced at the individual level by people in close proximity to one another. It is difficult to ignore the hardships of people right next to you; thus, the most noticeable behaviors may be those specifically related to individuals. Many 
of the OCBI items fit directly into the types of helping behavior one might see at work after a disaster (e.g., "Show genuine concern and courtesy toward coworkers, even under the most trying business or personal situations"). In contrast, the OCBO items may seem much less important after a disaster (e.g., "Show pride when representing the organization in public").

The finding that individuals engaged in an approach coping style were less influenced by informational justice perceptions at time 3 than at time 2 may be explained by using uncertainty management theory. It is not unreasonable to assume that uncertainty created by the hurricane was stronger at time 2 than at time 3 , causing justice perceptions to have more impact in earlier time periods. During the four week period from time 2 to time 3, at least some repairs and cleanup would have been completed, reducing overall uncertainty to some degree at time 3 . However, uncertainty could be very salient at time 2 for people trying to juggle work duties with home repairs, especially regarding informational justice issues such as explanations about altered work procedures or schedules in response to the hurricane. If individuals engaging in an approach coping style cannot get closure on the hurricane, the resulting uncertainty could lead to more reliance on justice perceptions in predicting OCB. Indeed, uncertainty management theory states that fairness will matter more for employee behavior when employees are experiencing uncertainty (Lind and Van den Bos 2002). As overall uncertainty is reduced at time 3 (and individuals engaging in approach coping are likely to take an active role to reduce uncertainty), justice perceptions become less influential in predicting employee behavior.

Although overall uncertainty is likely to be stronger at time 2 as discussed above, the interpersonal aspects of being treated politely and with respect may not be very meaningful to individuals focused on solving problems associated with the hurricane if there is a general societal expectation of polite treatment. This statement is based on results showing a direct positive relationship between interpersonal justice and OCBI, but a negative interaction of interpersonal justice $\mathrm{x}$ approach coping style on OCBI. Individuals using an approach coping style may be less concerned with interpersonal justice, in general, and more concerned with concrete results.

Interpersonal justice perceptions are based partly upon making social comparisons with how others are treated. For example, individuals judge whether a particular action is respectful or not based on observing examples of both respectful and disrespectful behavior. Gibbons and Buunk (1999) proposed that individuals who engaged in high levels of social comparisons were chronically uncertain, while Thau et al. (2007) found that people who are high in social comparison orientation react 
more strongly to fairness information than those who are lower in social comparison orientation. Thus, people who experience low levels of uncertainty, such as those who engage in approach coping, are less anxious and are likely to make fewer social comparisons in interpersonal justice judgments. Therefore, they are less likely to let justice perceptions influence their organizational behavior regardless of time period.

\section{CONCLUSIONS AND FUTURE STUDY}

Studies of justice over time are rare, perhaps because good quality longitudinal data is difficult to obtain. However, the robust nature of organizational justice suggests that longitudinal justice studies may enhance our understanding of how to utilize this construct in a practical and meaningful way in the workplace. For example, cross-sectional studies often refer to the fairness effect (Folger et al. 1979) in which individuals who believe a decision process or outcome is fair are more accepting of the outcome than those who do not believe the process or outcome is fair, but does this effect continue over time? The present study and some earlier studies have found that either the effects of justice perceptions or the perception of justice itself may change over time (Ambrose and Cropanzano 2003; Hausknecht et al. 2011; Holtz and Harold 2009; Lilly et al. 2010; Thornhill and Saunders 2003).

One limitation of the present study includes attrition. The first survey administration produced 255 surveys, the second produced 218 surveys $(85.4 \%$ retention rate), and the third produced 213 surveys ( $83.5 \%$ retention rate). To deal with participant attrition, and to ensure no self-selection or possible participant non-random bias had occurred, we used a procedure recommended by Goodman and Blum (1996). Specifically, a dichotomous variable was created to differentiate between participants who responded to all three surveys (stayers) and participants who responded only to Time 1 (leavers). Logistic regression was performed using the dichotomous variable of stayer/leaver as the dependent variable and interpersonal justice time 1, informational justice time 1, OCBI time 1, and OCBO time 1 as the independent variables. Results indicated that none of the regression coefficients were significant $(p<.84$ for interpersonal justice; $p<.79$ for informational justice; $p<.19$ for OCBI; $p<.10$ for OCBO), suggesting there was no non-random bias in the data. Although there was no direct measure or manipulation of uncertainty, we believe the context of a natural disaster provides an environment of uncertainty that can be assumed when using fairness heuristic theory and uncertainty management theory as the basis for hypotheses. Indeed, Lind and Van den Bos (2002) suggest that times of turmoil (e.g., the aftermath of a hurricane) create a level of uncertainty most 
likely to need fairness-related actions.

One practical implication of the present study for managers is the knowledge that employee coping style may increase or reduce the influence of fair procedures in the workplace. Presumably, organizations will want employees to engage in approach coping strategies at work since this coping behavior focuses on resolving the situation for the individual employee as well as others affected by the stressful situation. Training employees in approach coping strategies might be useful, therefore, in reducing response time to customer complaints or reducing the time needed to resolve typical workplace issues such as interdepartmental disputes. However, employees engaged in approach coping behavior tend to be less influenced by justice perceptions, possibly making major investments in fair procedures and the communication of those procedures to employees a costly endeavor with fewer benefits than expected. Of course, for ethical reasons and legal reasons, managers should attempt to create and implement fair procedures in the workplace. However, early studies on the fairness effect (Folger, et al., 1979) suggesting that fair procedures ameliorate negative employee reactions to work decision outcomes may be too comprehensive in scope by painting a majority of employees with one brush.

Future research should focus on providing a unifying theory of justice over time. We believe fairness heuristic theory and uncertainty management theory are good starting points for this discussion, and greater understanding of longitudinal justice perceptions will enhance our ability to bring academic research closer to practical management application. We specifically acknowledge the contribution by Lind and Van den Bos (2002) suggesting there is a cost to fair procedures; sometimes it is more efficient and more cost-effective to use procedures that are less fair. Thus, researchers need to develop a more comprehensive perspective of how justice influences individuals over time, so that organizations will not waste an investment of time and resources into procedures that may not be beneficial.

\section{REFERENCES}

Adams, J. S. (1963). Toward an understanding of inequity. Journal of Abnormal and Social Psychology, 67(5), 422-436.

Ambrose, M. L., \& Cropanzano, R. (2003). A longitudinal analysis of organizational fairness: An examination of reactions to tenure and promotion decisions. Journal of Applied Psychology, 88, 266-275. 
Aquino, K. (1995). Relationships among pay inequity, perceptions of procedural justice and organizational citizenship. Employee Responsibilities and Rights Journal, 8(1), 21-33.

Barclay, L. J. \& Kiefer, T. (2014). Approach or Avoid? Exploring overall justice and the differential effects of positive and negative emotions. Journal of Management, 40(7), 1857-1898.

Barker, D. B. (2007). Antecedents of stressful experiences: Depressive symptoms, self-esteem, gender, and coping. International Journal of Stress Management, 14(4), 333-349.

Bauer, T. N., Maertz, C. P., Dolen, M. R., \& Campion, M. A. (1998). Longitudinal assessment of applicant reactions to employment testing and test outcome feedback. Journal of Applied Psychology, 83(6), 892-903.

Blau, P. (1964). Exchange and power in social life. New York, NY: Wiley.

Chin, W. W., Marcolin, B. L., \& Newsted, P. R. (2003). A partial least squares latent variable modeling approach for measuring interaction effects: Results from a Monte Carlo simulation study and an electronic-mail emotion/adoption study. Information Systems Research, 14(2), 189-217.

Colquitt, J. A. (2001). On the dimensionality of organizational justice: A construct validation of a measure. Journal of Applied Psychology, 86(3), 386-400.

Colquitt, J.A., \& Rodell, J. B. (2011). Justice, trust and trustworthiness: A longitudinal analysis integrating three theoretical perspectives. Academy of Management Journal, 54(6), 1183-1206.

Cropanzano, R., Prehar, C. A., \& Chen, P. Y. (2002). Using social exchange theory to distinguish procedural from interactional justice. Group \& Organization Management, 27(3), 324-351.

Duhachek, A., \& Oakley, J. L. (2007). Mapping the hierarchical structure of coping: Unifying empirical and theoretical perspectives. Journal of Consumer Psychology, 17(3), 216-233.

Eaton, J., \& Struthers, C. W. (2002). Using the internet for organizational research: A study of cynicism in the workplace. CyberPsychology \& Behavior, 5(4), 305313.

Fassina, N. E., Jones, D. A., \& Uggerslev, K. L. (2008). Relationship clean-up time: Using meta-analysis and path analysis to clarify relationships among job satisfaction, perceived fairness, and citizenship behaviors. Journal of Management, 34(2), 161-188. 
FEMA. Aug 11, 2010. Hurricane Ike six months later: Confronting the challenges - in partnership. http:/www.fema.gov/hazard/hurricane/2008/ike/anniversary. shtm

Folger, R., Rosenfield, D., Grove, J., \& Corkran, L. (1979). Effects of "voice" and peer opinions on responses to inequity. Journal of Personality and Social Psychology, 37(12), 2253-2261.

Folkman, S., \& Moskowitz, J. T. (2004). Coping: Pitfalls and promise. Annual Review of Psychology, 55, 745-774.

Fornell, C., \& Larcker, D. F. (1981). Evaluating structural equation models with unobservable variables and measurement error. Journal of Marketing Research, 18(1), 39-50.

Gefen, D., \& Straub, D. (2005). A practical guide to factorial validity using PLSgraph: Tutorial and annotated example. Communications of the Association for Information Systems, 16, 91-109.

Gibbons, F. X., \& Buunk, B. P. (1999). Individual differences in social comparison: Development of a scale of social comparison orientation. Journal of Personality and Social Psychology, 76(1), 129-142.

Goodman, J. S., \& Blum, T. C. (1996). Assessing the non-random sampling effects of subject attrition in longitudinal research. Journal of Management, 22(4), 627652.

Greenberg, J. (2006). Losing sleep over organizational injustice: Attenuating insomniac reactions to underpayment inequity with supervisory training in interactional justice. Journal of Applied Psychology, 91, 58-69.

Greenberg, J., \& Folger, R. (1983). Procedural justice, participation, and the fair process effect in groups and organizations. In P. B. Paulus (Ed.), Basic group processes (pp. 235-256). New York, NY: Springer-Verlag.

Hausknecht, J. P., Sturman, M. C., \& Roberson, Q. M. (2011). Justice as a dynamic construct: Effects of individual trajectories on distal work outcomes. Journal of Applied Psychology, 96(4), 872-880.

Hochwarter, W. A., Laird, M. D., \& Brouer, R. L. (2008). Board up the windows: The interactive effects of hurricane-induced job stress and perceived resources on work outcomes. Journal of Management, 34(2), 263-289.

Holahan, C. J., \& Moos, R. H. (1990). Life stressors, resistance factors, and improved psychological functioning: An extension of the stress resistance paradigm. Journal of Personality and Social Psychology, 58(5), 909-917. 
Holahan, C. J., \& Moos, R. H. (1991). Life stressors, personal and social resources, and depression: A 4-year structural model. Journal of Abnormal Psychology, 100(1), 31-38.

Holahan, C. J., Moos, R. H., Holahan, C. K., \& Brennan, P. L. (1997). Social context, coping strategies, and depressive symptoms: An expanded model with cardiac patients. Journal of Personality and Social Psychology, 72(4), 918-928.

Holtz, B. C., \& Harold, C. M. (2009). Fair today, fair tomorrow? A longitudinal investigation of overall justice perceptions. Journal of Applied Psychology, 94(5), 1185-1199.

Jandeska, K. E., \& Kraimer, M. L. (2005). Women's perceptions of organizational culture, work attitudes, and role-modeling behaviors. Journal of Managerial Issues, 17(4), 461-478.

Judge, T. A., \& Colquitt, J. A. (2004). Organizational justice and stress: The mediating role of work-family conflict. Journal of Applied Psychology, 94(5), 1185-1199.

Kim, T., Lin, X. \& Leung, K. (2015). A dynamic approach to fairness: Effects of temporal changes of fairness perceptions on job attitudes. Journal of Business and Psychology, 30, 163-175.

Lang, J., Bliese, P. D., Lang, J. W. B., \& Adler, A. B. (2011). Work gets unfair for the depressed: Cross-lagged relations between organizational justice perceptions and depressive symptoms. Journal of Applied Psychology, 89, 395-404.

Lazarus, R. S. (1993). Coping theory and research: past, present and future. Psychosomatic Medicine, 55, 234-247.

Lee, K., \& Allen, N. J. (2002). Organizational citizenship behavior and workplace deviance: The role of affect and cognitions. Journal of Applied Psychology, 87(1), 131-142.

Lilly, J. D., Virick, M., \& Hadani, M. (2010). The dynamic nature of justice: Influential effects of time and work outcomes on long-term perceptions of justice. Social Justice Research, 23(1), 37-59.

Lind. E. A. (2001). Fairness heuristic theory: Justice judgments as pivotal cognitions in organizational relations. In J. Greenberg and R. Cropanzano (Eds.), Advances in organizational justice (pp. 56-88). Stanford, CA: Stanford University Press.

Lind, E. A., \& Van den Bos, K. (2002). When fairness works: Toward a general theory of uncertainty management. In B. M. Staw \& R. M. Kramer (Eds.), Research in organizational behavior (vol. 24, pp. 181-223). Boston, MA: Elsevier.

Marjanovic, Z., Struthers, C. W., \& Greenglass, E. R. (2012). Who helps naturaldisaster victims? Assessment of trait and situational predictors. Analyses of Social Issues and Public Policy, 12(1), 245-267. 
Masterson, S. S., Lewis, K., Goldman, B. M., \& Taylor, M. S. (2000). Integrating justice and social exchange: The differing effects of fair procedures and treatment on work relationships. Academy of Management Journal, 43(4), 738-748.

McManus, J. L., \& Saucier, D. A. (2012). Helping natural disaster victims depends on characteristics and perceptions of victims. A response to "Who helps natural disaster victims?" Analyses of Social Issues and Public Policy, 12(1), 272-275.

McNeely, B. L., \& Meglino, B. M. (1994). The role of dispositional and situational antecedents in prosocial organizational behavior: An examination of the intended beneficiaries of prosocial behavior. Journal of Applied Psychology, 79(6), 836-844.

Moorman, R. H., \& Byrne, Z. S. (2005). How does organizational justice affect organizational citizenship behavior? In J. Greenberg and J. A. Colquitt (Eds.), Handbook of organizational justice (pp. 355-380). Mahwah, NJ: Erlbaum.

Moos, R. (1993). Coping Responses Inventory - Adult Form Manual. Odessa, FL: Psychological Assessment Resources.

Moos, R. H., \& Holahan, C. J. (2003). Dispositional and contextual perspective on coping: Toward an integrative framework. Journal of Clinical Psychology, 59(12), 1387-1403.

Nunnally, J. C. (1978). Psychometric Theory (2nd ed.). New York, NY: McGrawHill.

Pakenham, K. I. (2006). Investigation of the coping antecedents to positive outcomes and distress in multiple sclerosis. Psychology \& Health, 21(5), 633-649.

Podsakoff, P. M., Mackenzie, S. B., Paine, J. B., \& Bachrach, D. G. (2000). Organizational citizenship behaviors: A critical review of the theoretical and empirical literature and suggestions for future research. Journal of Management, 26(3), 513-563.

Podsakoff, P. M., MacKenzie S. B., Lee J., \& Podsakoff N. P. (2003). Common method biases in behavioral research: A critical review of the literature and recommended remedies. Journal of Applied Psychology, 88(5), 879-903.

Posthuma, R. A., Dworkin, J. B., \& Swift, M. S. (2000). Arbitrator acceptability: Does justice matter? Industrial Relations, 39(2), 313-335.

Ringle, C. M., Wende, S., \& Will, S. (2005). SmartPLS 2.0 (M3) Beta [Software]. Available from http://www.smartpls.de/

Roth, S., \& Cohen, L. J. (1986). Approach, avoidance, and coping with stress. American Psychologist, 41(7), 813-819.

Rotondo, D. M., Carlson, D. S., \& Kincaid, J. F. (2003). Coping with multiple dimensions of work-family conflict. Personnel Review, 32(3), 275-296. 
Scheck, C. L., \& Kinicki, A. J. (2000). Identifying the antecedents of coping with an organizational acquisition: A structural assessment. Journal of Organizational Behavior, 21(6), 627-648.

Tangirala, S., \& Alge, B. J. (2006). Reactions to unfair events in computer-mediated groups: A test of uncertainty management theory. Organizational Behavior and Human Decision Processes, 100(1), 1-20.

Tekleab, A. G., Takeuchi, R., \& Taylor, M. S. (2005). Extending the chain of relationships among organizational justice, social exchange, and employee reactions: The role of contract violations. Academy of Management Journal, 48(1), 146-157.

Thau, S., Aquino, K., \& Wittek, R. (2007). An extension of uncertainty management theory to the self: The relationship between justice, social comparison orientation, and antisocial work behaviors. Journal of Applied Psychology, 92(1), 250-258.

Thau, S., Bennett, R. J., Mitchell, M. S., \& Marrs, M. B. (2009). How management style moderates the relationship between abusive supervision and workplace deviance: An uncertainty management theory perspective. Organizational Behavior and Human Decision Processes, 108(1), 79-92.

Thornhill, A., \& Saunders, M. K. (2003). Exploring employees' reactions to strategic change over time: The utilization of an organizational justice perspective. Irish Journal of Management, 24(1), 66-86.

Timko, C., Cronkite, R. C., \& Moos, R. H. (2010). Do parental stressors and avoidance coping mediate between parental depression and offspring depression? A 23year follow-up. Family Relations, 59(2), 121-135.

Tobin, S. J., \& Raymundo, M. M. (2010). Causal uncertainty and psychological well-being: The moderating role of accommodation. Personality and Social Psychology Bulletin, 36(3), 371-383.

Treadway, D. C., Hochwarter, W. A., Kacmar, C. J., \& Ferris, G. R. (2005). Political will, political skill, and political behavior. Journal of Organizational Behavior, 26(3), 229-245.

Valentiner, D. P., Holahan, C. J., \& Moos, R. H. (1994). Social support, appraisals of event controllability, and coping: An integrative model. Journal of Personality and Social Psychology, 66(6), 1094-1102.

Van den Bos, K. (2001). Uncertainty management: The influence of uncertainty salience on reactions to perceived procedural fairness. Journal of Personality and Social Psychology, 80(6), 931-941. 
Van den Bos, K., \& Lind, E. A. (2002). Uncertainty management by means of fairness judgments. In M. P. Zanna (Ed.), Advances in experimental social psychology (vol. 34, pp. 1-60). Boston, MA: Elsevier.

Van den Bos, K., \& Miedema, J. (2000). Toward understanding why fairness matters: The influence of mortality salience of reactions to procedural fairness. Interpersonal Relations and Group Processes, 79(3), 355-366.

Van den Bos, K., Vermunt, R., \& Wilke, H. A. M. (1997). Procedural and distributive justice: What is fair depends more on what comes first than on what comes next. Journal of Personality and Social Psychology, 72(1), 95-104.

Vitaliano, P.P., Maiuro, R. D., Russo, J., \& Becker, J. (1987). Raw versus relative scores in the assessment of coping strategies. Journal of Behavioral Medicine, 10(1), 1-18.

Williams, L. J., \& Anderson, S. E. (1991). Job satisfaction and organizational commitment as predictors of organizational citizenship and in-role behaviors. Journal of Management, 17(3), 601-617.

\section{BRIEF BIOGRAPHICAL SKETCH OF AUTHORS}

Juliana D. Lilly is a Professor of Management at Sam Houston State University. She holds degrees in Hotel/Restaurant Management (B.S.), Organizational Management (M.B.A.), and Organizational Behavior (Ph.D.). After ten years of industry experience, she entered graduate school and was awarded the Ph.D. in Business Administration from The University of Texas at Arlington. Dr. Lilly's research interests include organizational justice, psychological contract violations, and outsourcing. She has presented research at numerous international, national, and regional academic meetings. Her publications appear in journals such as Journal of Organizational Behavior, Social Justice Research, Current Psychology, and Journal of Behavioral and Applied Management.

Meghna Virick is a Professor at San Jose State University, specializing in Human Resource Management. She earned her Ph.D. from the University of Texas at Arlington, a Masters in Industrial Relations from XLRI, India, and an MBA from Texas Christian University. Her areas of research include unemployment/ underemployment, as well as gender and age related issues in HR practices such as talent and succession planning. Her academic work has been published in journals such as the Journal of Organizational Behavior, Human Relations, Group \& Organization Management, Journal of Applied Psychology, and Human Resource Management Journal. Her comments on current HR issues have been the topic of 
numerous stories in print and broadcast media.

Kamphol Wipawayangkool is an Assistant Professor of Management Information Systems at Sam Houston State University. He received his Ph.D. in Information Systems from the University of Texas at Arlington, M.S. in Management Information Systems from University of Houston-Clear Lake, and B.S. in Computer Science from Prince of Songkla University, Thailand. His research has appeared in Knowledge Management Research \& Practice, Journal of Information \& Knowledge Management, Journal of Knowledge Management Practice, and Issues in Information systems.

Note: An earlier version of this paper was presented at the Southwest Academy of Management meeting in Albuquerque, NM, March 2013. 